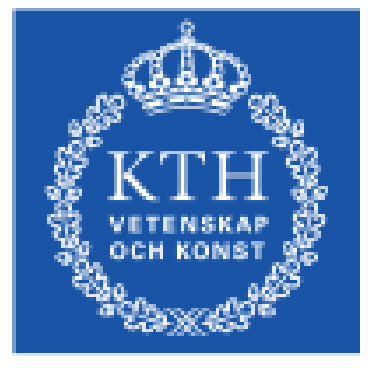

ROYAL INSTITUTE

OF TECHNOLOGY

\title{
Determination of a gravimetric geoid model of Greece using the method of KTH
}

\author{
Ilias Daras
}

Master's of Science Thesis in Geodesy No. 3102

TRITA-GIT EX 08-002

Royal Institute of Technology (KTH)

School of Architecture and the Built Environment

10044 Stockholm, Sweden

January 2008 


\section{Acknowledgments}

First of all, I would like to express my gratitude to my supervisor in KTH, Dr. Huaan Fan and my supervisor in NTUA, Professor Kalliopi Papazissi for their guidance and support throughout this project.

Special thanks go to Professor Derek Fairhead of Leeds University and GETECH for providing the gravity data for Greece and to Mr. Antonis Angelopoulos for his help. Many thanks go to Dr. Artu Ellmann for his continuous help and for providing me his, essential for the computations, Matlab software package and to Dr. Ramin Kiamehr for their help throughout this project. I would also like to express my gratitude to Professor Lars Sjöberg for sharing his knowledge and for his valuable comments.

I would also like to thank $\mathrm{PhD}$ students in NTUA Aggeliki Marinou and Nikos Tzelepis for their help in collecting the dataset. Many thanks go to my colleagues in Stockholm and to all my friends for being there for me.

At last, a big thank you goes to my parents for their love and support during all the years of my studies. 
The main purpose of this study is to compute a gravimetric geoid model of Greece using the least squares modification method developed at KTH. In regional gravimetric geoid determination, the modified Stokes's formula that combines local terrestrial data with a global geopotential model is often used nowadays.

In this study, the optimum modification of Stokes's formula, introduced by Professor Sjöberg, is employed so that the expected mean square error (MSE) of all possible solutions of the general geoid model is minimized. According to this stochastic method, the Stokes's formula is being used with the original surface gravity anomaly which combined with a GGM yields an approximate geoid height. The corrected geoid height is then obtained by adding the topographic, downward continuation, atmospheric and ellipsoidal corrections to the approximate geoid height.

The dataset used for the computations, consisted of terrestrial gravimetric measurements, a DEM model and GPS/Levelling data for the Greek region. Three global geopotential models (EGM96, EIGEN-GRACE02S, EIGEN-GL04C) were tested for choosing the best GGM to be combined into the final solution. Regarding the evaluation and refinement of the terrestrial gravity measurements, the cross-validation technique has been used for detection of outliers.

The new Greek gravimetric geoid model was evaluated with 18 GPS/Levelling points of the Greek geodetic network. The absolute agreement between the gravimetric and the GPS/Levelling geoid height was estimated at $27 \mathrm{~cm}$ while the relative agreement at $0.9 \mathrm{ppm}$. In a case of study the absolute accuracy of the model was estimated at $14 \mathrm{~cm}$. The geoid model computed in this study was also compared with some previous Greek geoid models, yielding better external accuracy than them.

Keywords: Gravimetric geoid, Least Squares Modification of Stokes's formula, Optimum modification, GPS/levelling, Greek geoid 


\section{Abbreviations}

DEM $=$ Digital Elevation Model

DWC $=$ Downward Continuation

EGM= Earth Gravity Model

FFT $=$ Fast Fourrier Transform

GRACE $=$ Gravity Recovery And Climate Experiment

GGM $=$ Global Geopotential Model

GFZ $=$ GeoForschungsZentrum Potsdam

$\mathrm{IAG}=$ International Association of Geodesy

KTH $=$ Kunglika Tekniska Högskolan

LSMS = Least Square Modification of Stokes's (formula)

MSE $=$ Mean Square Error

NTUA $=$ National Technical University of Athens

RTM $=$ Residual Terrain Model

RMS $=$ Root Mean Square

SVD $=$ Singular Value Decomposition 


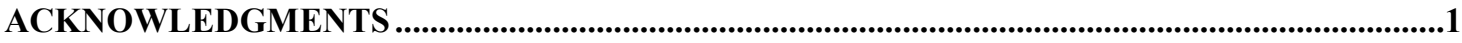

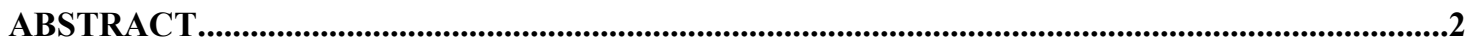

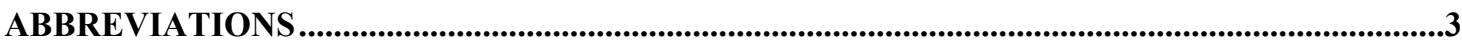

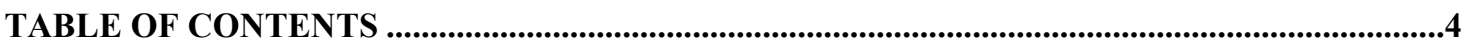

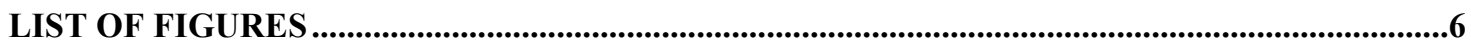

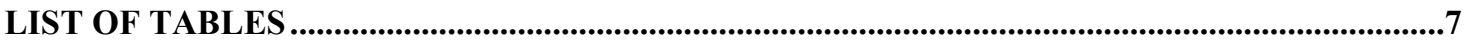

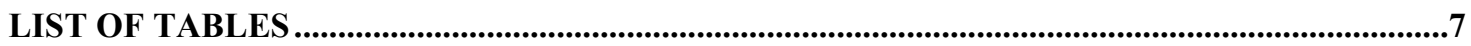

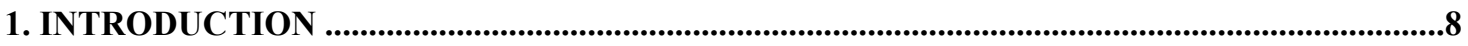

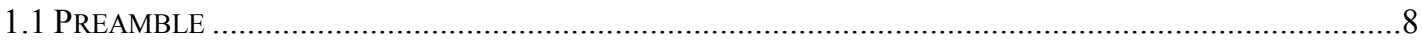

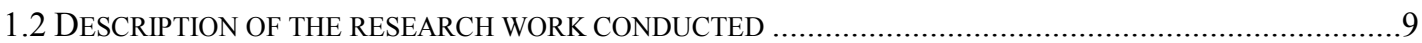

2. GEOID DETERMINATION BASED ON THE LEAST-SQUARES MODIFICATION OF

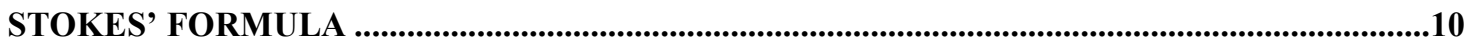

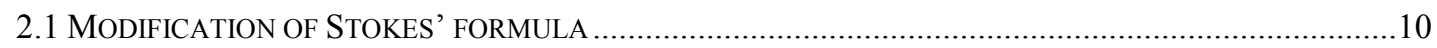

2.2 MODELS FOR SIGNAL AND NOISE DEGREE VARIANCES ............................................................ 14

2.3 DETERMINATION OF THE LEAST-SQUARES MODIFICATION PARAMETERS.......................................17

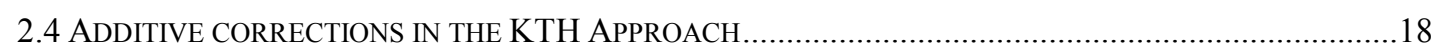

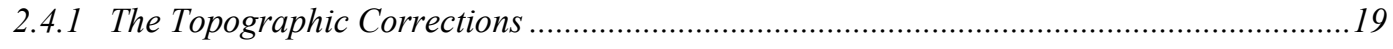

2.4.2 The Downward Continuation Correction ....................................................................20

2.4.3 The Atmospheric Correction ...........................................................................................21

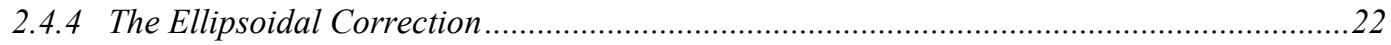

3. CONSTRUCTION AND EVALUATION OF THE DATA BASES..............................................24

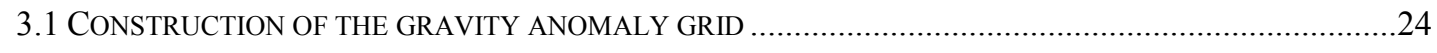

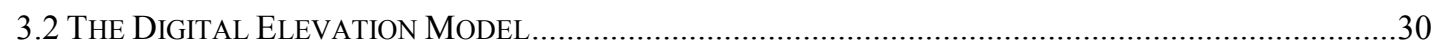

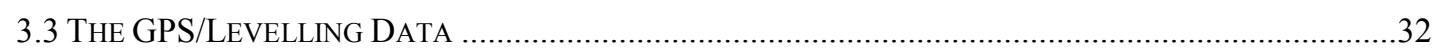

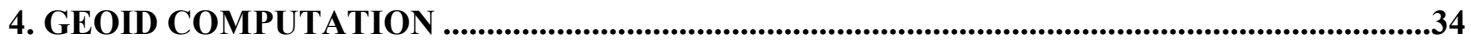

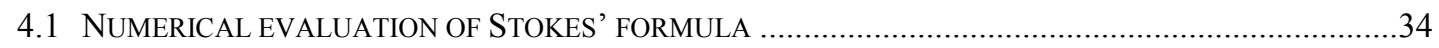

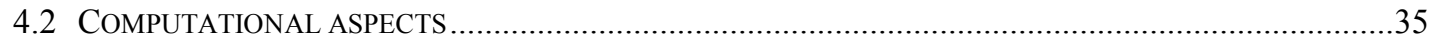

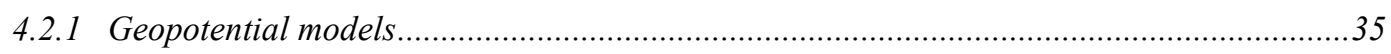

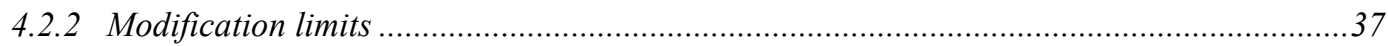

4.3 The New GRAVIMETRIC GeOID ModeL …............................................................................ 41

5. EVALUATION OF THE GRAVIMETRIC GEOID MODEL .....................................................44 
5.1 OVERVIEW OF CURRENT GREEK GEOID MODELS.. .44

5.2 THEORETICAL ESTIMATE OF THE ACCURACY OF THE GRAVIMETRIC GEOID MODEL .47

5.3 EXTERNAL ESTIMATION OF THE ACCURACY OF THE GRAVIMETRIC GEOID MODEL ........................48

5.3.1 Agreement of absolute geoid heights...... .49

5.3.2 Agreement of the relative geoid heights .56

6. CONCLUSIONS AND RECOMMENDATIONS.. .58

REFERENCES .62

REPORTS IN GEOGRAPHIC INFORMATION TECHNOLOGY 2007-2008. .67

THE TRITA-GIT SERIES - ISSN 1653-5227 .67 


\section{List of Figures}

FIG. 3.1: ABSOLUTE VALUES OF THE INTERPOLATION ERROR OF BOUGUER GRAVITY ANOMALIES USING CROSS VALIDATION TECHNIQUE

FIG. 3.2: ABSOLUTE VALUES OF THE DIFFERENCES BETWEEN THE GRAVITY ANOMALIES OF MOLODENSKII AND THE EGM96 FREE-AIR GRAVITY ANOMALIES.

FIG. 3.3: LOCATION OF THE TARGET AREA IS ENCLOSED BY THE SMALLER/BOLD RECTANGLE. EXTERNAL RECTANGLE ENCLOSES THE TARGET AREA AT A SPHERICAL DISTANCE OF $3^{\circ}$ DEGREES FROM ITS BORDERS.

FIG. 3.4: DENSITY OF GRAVITY MEASUREMENTS IN A $1^{0} \times 1^{0}$ GRID. EACH BLOCK SHOWS THE NUMBER OF THE GRAVITY DATA POINTS THAT WERE INCLUDED IN THE BLOCK. THE GPS/LEVELLING POINTS USED IN THE EVALUATION ARE ALSO SHOWN.

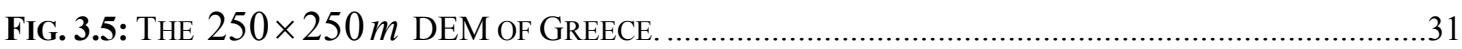

FIG. 4.1: BEHAVIOR OF THE LS MODIFIED STOKES FUNCTION....

Fig. 4.2: BEHAVIOR OF THE LS MODIFIED STOKES FUNCTION $S^{L}(\psi)$ FOR EIGEN-GL04C MODEL WITH MODIFICATION DEGREE $M=L=360$ AND CAP SIZE $\psi_{0}=3^{\circ}$

Fig. 4.3: BEHAVIOR OF THE LS MODIFIED STOKES FUNCTION $S^{L}(\psi)$ FOR EIGEN-GRACE02S MODEL WITH MODIFICATION DEGREE $M=L=120$ AND CAP SIZE $\psi_{0}=3^{\circ}$

FIG. 4.4: COMBINED TOPOGRAPHIC EFFECT FOR THE NEW GREEK GRAVIMETRIC GEOID MODEL. UNIT: M 41

FIG. 4.5: ELLIPSOIDAL CORRECTION FOR THE NEW GREEK GRAVIMETRIC GEOID MODEL. UNIT: MM ........42

FIG. 4.6: COMBINED ATMOSPHERIC CORRECTION FOR THE NEW GREEK GRAVIMETRIC GEOID MODEL. UNIT: MM

FIG. 4.7: THE NEW GREEK GRAVIMETRIC GEOID MODEL IN GRS80 ….................................................4

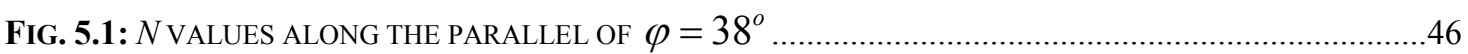

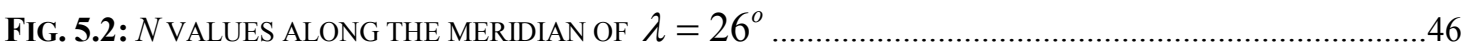

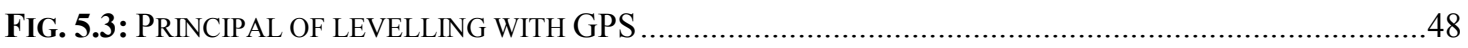

FIG. 5.4: DISTRIBUTION OF THE GPS/LEVELLING POINTS INSIDE THE GREEK REGION. THE ABSOLUTE VALUE OF THE RESIDUALS $\varepsilon_{i}$ WITH THE GEOID MODEL AFTER THE 7-PARAMETER FITTING IS VISUALIZED WITH THE DIFFERENCE IN THE COLOR SCALE. 


\section{List of Tables}

TABLE 3.1: COORDINATES OF THE GPS/LEVELLING POINTS USED FOR THE EVALUATION. THE ORTHOMETRIC AND GEOID HEIGHT VALUES ARE ALSO SHOWN.

TABLE 4.1: INPUT PARAMETERS THAT WERE CHOSEN FOR COMPUTING THE $S_{n}$ and $b_{n}$ LS PARAMETERS WITH LSCOEFF.M PROGRAM. .38

TABLE 5.1: GEOID HEIGHT VALUES FROM GPS/LEVELLING AND FROM THE NEW GRAVIMETRIC GEOID ...48

TABLE 5.2: GEOID HEIGHT DIFFERENCES BETWEEN THE GPS AND THE APPROXIMATE GEOID VALUES, BEFORE AND AFTER THE 7-PARAMETER FITTING. RESULTS ARE DISPLAYED FOR ALL THE GGM MODELS USED.

TABLE 5.3: GEOID HEIGHT DIFFERENCES BETWEEN THE GPS AND THE FINAL GEOID VALUES, BEFORE AND AFTER THE 7-PARAMETER FITTING. RESULTS ARE DISPLAYED ONLY FOR THE EIGEN-GRACE02S MODEL WHICH WAS CHOSEN FOR THE COMPUTATIONS.

TABLE 5.4: ESTIMATION OF THE AGREEMENT BETWEEN THE RELATIVE VALUES OF THE GRAVIMETRIC AND GPS/LEVELLING DERIVED GEOID HEIGHT .57 


\section{Chapter 1}

\section{Introduction}

\subsection{Preamble}

One of the major tasks of geodesy is the determination of the geoid, which is defined as an equipotential surface of the Earth gravity field, which coincides on average with mean sea level. The geoid surface is more irregular than the ellipsoid of revolution often used to approximate the shape of the physical Earth, but considerably smoother than the Earth's physical surface. Nowadays, with technology advancing so quickly, GPS positioning can offer a very accurate determination of ellipsoid height $h$ relative to the ellipsoid. Precise knowledge of the geoid undulation relative to the ellipsoid $N$, can lead to the estimation of orthometric height $H$ by using the equation $h=H+N$ which connects those three values. Thus, one of the primal goals of geodesy is to develop a precise geoid model, which can then be used for computing the orthometric heights. The determination and availability of a high-resolution and more accurate geoid model, is a necessity in several geosciences e.g. detecting the variations of the ocean currents, study of the interior properties of the Earth in geophysics, seismology and plate tectonics since it serves as the reference surface for other measurements and phenomena. Geoid is also important information for other disciplines related to Geomatics engineering like navigation, mapping, surveying and construction.

New developments and advances in the gravity field determination from satellite tracking have taken place in the last few years. Recent satellite gravity missions, such as Gravity Recovery and Climate Experiment (GRACE) have provided global scale and very accurate gravity data. However, the up-to-date, accuracy of the global geoid modelling is a few decimetres, which is not sufficient for many scientific and engineering applications. So, high resolution regional geoid models are still necessary for the most practical purposes. 


\subsection{Description of the research work conducted}

Many different methods for regional geoid determination have been proposed through the years. Each method uses its own technique and has its own philosophy . The common goal among geodesists is to determine the "1-cm geoid model". Such an accurate geoid model requires more precise and denser gravity data around the point of computation than has been used in the past and the theory for modelling the geoid must be refined for the task.

Frequently, the mathematical procedures for determining the geoid are based on a traditional method of correcting the surface gravity anomaly for the reduction of the forbidden topographic and atmospheric masses outside the geoid. In addition there is a small ellipsoidal correction to be added to the gravity anomaly in order to be consistent with the spherical boundary used in Stokes' formula. As a result of the Stokes integration the co-geoid is obtained which then must be corrected for the indirect effects of topography, atmosphere and the correction from the sphere of computation to the ellipsoidal shape of the Earth.

The main purpose of this work is to determine a gravimetric geoid model for Greece, using the least squares modification method developed at KTH (Sjöberg 2003d). According to this method, instead of computing the co-geoid by correcting the gravity anomaly prior to Stokes integration, Stokes formula is being used with the original surface gravity anomaly, yielding an approximate geoid height. The corrected geoid height is obtained by adding the topographic, atmospheric, ellipsoidal effect and the correction for the downward continuation effect, to the approximate geoid height. Then

the geoid model is evaluated by comparing its values with externally derived geoid heights from GPS/Levelling data.

Gravity data for Greece were provided by the Geophysical Exploration Technology (GETECH) and DEM along with GPS/Levelling data were provided by the National Technical University of Athens (NTUA). 


\section{Chapter 2}

\section{Geoid determination based on the least-squares modification of Stokes' formula}

\subsection{Modification of Stokes' formula}

In 1849 one of the most important formulas in physical geodesy was published. This formula allows the determination of the geoidal height $(N)$ based on gravity data alone. It is known as Stokes' formula or Stokes' integral after George Gabriel Stokes. It reads:

$$
N=\frac{R}{4 \pi \gamma} \iint_{\sigma} S(\psi) \Delta g d \sigma
$$

where $R$ stands for the mean Earth radius, $\psi$ for the geocentric angle, $\Delta g$ for the gravity anomaly, $d \sigma$ for the infinitesimal surface element of the unit sphere $\sigma, \gamma$ for the normal gravity on the reference ellipsoid and $S(\psi)$ for the Stokes function. Stokes function can be expressed as a series of Legendre polynomials:

$$
S(\psi)=\sum_{n=2}^{\infty} \frac{2 n+1}{n-1} P_{n}(\cos \psi)
$$

If we introduce a variable $t=\cos \psi$, then Stokes function can be also written in a closed form:

$$
S(t)=\sqrt{\frac{2}{1-t}}-6 \sqrt{\frac{1-t}{2}}+1-5 t-3 \ln \left(\sqrt{\frac{1-t}{2}}+\frac{1-t}{2}\right)
$$

The integration expressed in equation (2.1.1) must be carried out over the whole earth. When computing a regional geoid in practise, the area of integration is limited to a spherical cap around the computation point. Molodenskii et all (1962) showed that the truncation error of the remote zone can be reduced by a modification of Stokes's 
formula, which combines the terrestrial gravity anomalies and the long wavelength (up to degree $M$ ) contribution from GGM.

Accuracy requirements in geodesy, geophysics and oceanography for detailed gravity field information amount to $1 \mathrm{mgal}$ for gravity anomalies. The related accuracy for geoid ranges from 1 to $2 \mathrm{~cm}$. In the pre-satellite era, the earth's gravity field was known with high accuracy only in a few regions of the world. Primarily, the available accurate gravity field information was based on terrestrial and airborne measurements. This implied that in large parts of the world there were virtually no gravity data available. With the artificial satellites came the first reliable Global Geopotential Model (GGM) and the possibility to generate global geoid models. By combining the information from the GGMs with Stokes' integration over local gravity data, local geoid models may be estimated. The GGM gives the long-wavelength information about the geoid and the geopotential, while the local gravity data gives the shortwavelength information. Due to the use of local instead of global gravity data coverage, Stokes' kernel will be truncated at the outer range of the data coverage. This leads to truncation errors due to the loss of gravity information from the neglected outer zones. These errors may either be ignored or reduced by the modification of Stokes' kernel.

Over the recent decades two distinct groups of modification approaches have been proposed in geodetic literature. These groups are often called deterministic and stochastic modification methods. The deterministic approaches principally aim at reducing the truncation bias only. No attempt is made to incorporate the accuracy estimates of the geopotential coefficients and terrestrial data, although the errors of both data-sets propagate into the solution of the geoidal height. In contrast to the deterministic approaches, the stochastic methods by Sjöberg (1980, 1981, 1984, 1991, 2003) and Wenzel $(1981,1983)$ attempt also to reduce the data (i.e., global geopotential model (GGM) and terrestrial) errors. The stochastic approach described below, applies additional information about the potential coefficients and the gravity anomaly errors in combination with least squares modification of Stokes's kernel to minimize the expected global Mean Square Error (MSE) (e.g. Sjöberg 1984 and 1991). 
Assuming a cap $\sigma_{o}$ with spherical radius $\psi_{o}$ of integration around the computation point, Sjöberg (2003d) presented a simple and general modification model for Stokes' formula by defining two sets of arbitrary modification parameters $\left(s_{n}\right.$ and $\left.b_{n}\right)$ as follows (cf. Sjöberg 2003d):

$$
\tilde{N}=\frac{c}{2 \pi} \iint_{\sigma_{o}} S^{L}(\psi) \Delta g d \sigma+c \sum_{n=2}^{M} b_{n} \Delta g_{n}^{E G M}
$$

where $b_{n}=\left(Q_{n}^{L}+s_{n}^{*}\right) \frac{c_{n}}{c_{n}+d c_{n}}$ for $2 \leq n \leq M, c=R / 2 \gamma$ and $\Delta g_{n}^{E G M}$ is the Laplace harmonics of degree $n$ and calculated from an EGM (Heiskanen and Moritz 1967 p.89).

$$
\Delta g_{n}^{E G M}=\frac{G M}{a^{2}}\left(\frac{a}{r}\right)^{n+2}(n-1) \sum_{m=-n}^{n} C_{n m} Y_{n m}
$$

where $a$ is the equatorial radius of the reference ellipsoid, $r$ is the geocentric radius of the computation point, GM is the adopted geocentric gravitational constant, the coefficients $C_{n m}$ are the fully normalized spherical harmonic coefficients of the disturbing potential provided by the GGM, and $Y_{n m}$ are the fully normalized spherical harmonics (Heiskanen and Moritz 1967, p.31) .

The modified Stokes's function is expressed as

$$
S^{L}(\psi)=\sum_{n=2}^{\infty} \frac{2 n+1}{n-1} P_{n}(\cos \psi)-\sum_{n=2}^{L} \frac{2 n+1}{2} S_{n} P_{n}(\cos \psi),
$$

where the first term on the right-hand side is the original Stokes function, $S(\psi)$, in terms of Legendre polynomials.

Generally the upper bound of the harmonics to be modified in Stokes's function, $L$, is arbitrary and not necessarily equal to the GGMs' upper limit, $M$. The truncation coefficients $Q_{n}^{L}=Q_{n}-\sum_{k=2}^{L} \frac{2 k+1}{2} S_{k} e_{n k}$

Where the Molodenskii's truncation coefficients $Q_{n}=\int_{\psi^{0}}^{\pi} S(\psi) P_{n} \cos (\psi) \sin (\psi) d \psi$, 
and $e_{n k}$ are functions of $\psi_{o}$ called Paul's coefficients (Paul 1973). By utilizing the error estimates of the data, and some approximations (both theoretical and computational), we arrive at an estimate of the geoid height that we call the approximate geoidal height, which can be written in the following spectral form (cf. Sjöberg 2003d, Eq.8a).

$$
\tilde{N}=c \sum_{n=2}^{\infty}\left(\frac{2}{n-1}-Q_{n}^{L}-s_{n}^{*}\right)\left(\Delta g_{n}+\varepsilon_{n}^{T}\right)+c \sum_{n=2}^{M}\left(Q_{n}^{L}+s_{n}^{*}\right)\left(\Delta g_{n}+\varepsilon_{n}^{S}\right)
$$

where $\varepsilon_{n}^{T}$ and $\varepsilon_{n}^{S}$ are the spectral errors of the terrestrial and GGM derived gravity anomalies, respectively. The modification parameters are:

$s_{n}^{*}=\left\{\begin{array}{l}s_{n} \text { if } 2 \leq n \leq L \\ 0 \text { otherwise }\end{array}\right.$

Based on the spectral form of the "true" geoidal undulation $N$ (Heiskanen and Moritz 1967, p. 97),

$$
N=c \sum_{n=2}^{\infty} \frac{2 \Delta g_{n}}{n-1}
$$

the expected global MSE of the geoid estimator $\tilde{N}$ can be written:

$$
\begin{aligned}
& m_{\tilde{N}}^{2}=E\left\{\frac{1}{4 \pi} \iint_{\sigma}(\tilde{N}-N)^{2} d \sigma\right\}= \\
& =c^{2} \sum_{n=2}^{M}\left(b_{n}^{2} d c_{n}\right)+c^{2} \sum_{n=2}^{\infty}\left[b_{n}^{*}-Q_{n}^{L}\left(\psi_{0}\right)-s_{n}^{*}\right]^{2} c_{n}+c^{2} \sum_{n=2}^{\infty}\left[\frac{2}{n-1}-Q_{n}^{L}\left(\psi_{0}\right)-s_{n}^{*}\right]^{2} \sigma_{n}^{2},
\end{aligned}
$$

where $E\{\}$ is the statistical expectation operator, $c_{n}$ are the gravity anomaly degree variances, $\sigma_{n}^{2}$ are the terrestrial gravity anomaly error degree variances, $d c_{n}$ are the GGM derived gravity anomaly error degree variances and

$$
b_{n}^{*}=\left\{\begin{array}{l}
b_{n} \text { if } 2 \leq n \leq L \\
0 \text { otherwise }
\end{array}\right.
$$


Equation (2.1.10) is an important formula since the LS (Least Square) modification aim at minimizing the global MSE of the geoid estimator. For simplicity, all data errors in Eq.(2.1.10) are assumed to be random and with zero expectations. The first term on the right side of Eq. (2.1.10) is due to the GGM errors; the middle term represents the truncation bias; and the last term accounts for the influence of erroneous data.

For the purposes of this study, a specially designed Matlab program made by Artu Ellmann (2005a) was used to obtain the LS parameters $s_{n}, b_{n}$ of the optimum LS modification method by Sjöberg (2003d). After that, the parameters were used as input to Matlab programs that were designed for the scope of this study, to derive the approximate geoidal height $\tilde{N}$.

\subsection{Models for signal and noise degree variances}

The gravity anomaly signal degree variances, the terrestrial gravity anomaly error degree variances and the GGM derived gravity anomaly error degree variances can be computed as follows:

$$
\begin{aligned}
& c_{n}=\frac{1}{4 \pi} \iint_{\sigma} \Delta g_{n}^{2} d \sigma, \\
& \sigma_{n}^{2}=E\left\{\frac{1}{4 \pi} \iint_{\sigma}\left(\varepsilon_{n}^{\mathrm{T}}\right)^{2} d \sigma\right\},
\end{aligned}
$$

and

$$
d c_{n}=E\left\{\frac{1}{4 \pi} \iint_{\sigma}\left(\varepsilon_{n}^{S}\right)^{2} d \sigma\right\}
$$

where $\varepsilon_{n}^{T}$ and $\varepsilon_{n}^{S}$ are the spectral errors of the terrestrial and GGM-derived gravity anomalies. 
The degree variance $c_{n}$ can be obtained by using coefficients $C_{n m}$ and $S_{n m}$ of disturbing potential and fundamental constants (gravity mass constant $G M$ and equatorial radius $a$ ) of the used GGM as follows:

$c_{n}=\frac{(G M)^{2}}{a^{4}}(n-1)^{2} \sum_{m=0}^{n}\left(C_{n m}^{2}+S_{n m}^{2}\right)$

In practice the infinite sum in Eq. (2.1.10), must be truncated at some upper limit of expansion; $n_{\max }=2000$ for our study. The higher signal degree variances can be generated synthetically. Among three well known models for estimation of the signal gravity anomaly degree variances [e.g. Kaula 1963, Tscherning and Rapp 1974 and Jekeli 1978], the Tscherning and Rapp model yields the most realistic values for the gravity anomaly truncation RMS errors and gives reasonable RMS values for geoidal heights (Ågren 2004a). So we decided to use this model to account for the highest degrees of gravity anomaly degree variance, which are defined by (Tscherning and Rapp,1974):

$c_{n}=A^{\prime} t^{n+2} \frac{(n-1)}{(n-2)(n+24)}$,

where the coefficients $A^{\prime}=425.28 m G a l^{2}$ and $t=0.999617$. However, this model is valid just for the gravity field uncorrected for any topographic effects. The error (noise) anomaly degree variance $\left(d c_{n}\right)$ of the erroneous potential coefficients is derived from the GGMs with standard errors $d_{C_{n m}}$ and $d_{S_{n m}}$ (cf. Rapp and Pavlis, 1990):

$d c_{n}=\frac{(G M)^{2}}{a^{4}}(n-1)^{2} \sum_{m=0}^{n}\left(d_{C_{n m}}^{2}+d_{S_{n m}}^{2}\right)$

The error degree variances for the terrestrial gravity anomalies can be estimated by using two different error degree variance models to represent gravity anomaly errors, 
namely the uncorrelated and the reciprocal distance models. For the latter, according to Moritz H. (1980) $\sigma_{n}^{2}$ can be estimated from the simple relation

$$
\sigma_{n}^{2}=c_{T}(1-\mu) \mu^{n}, \quad 0<\mu<1,
$$

where the constants $c_{T}$ and $\mu$ can be estimated from the knowledge of an isotropic error degree covariance function $C(\psi)$ presented in closed form (Sjöberg 1986):

$$
C(\psi)=c_{T}\left\{\frac{1-\mu}{\sqrt{1-2 \mu \cos \psi+\mu^{2}}}-(1-\mu)-(1-\mu) \mu \cos \psi\right\}
$$

Eq (2.2.8) is just a rough model for computing $\sigma_{n}^{2}$ and it is utilized for determining the constant $\mu$. For $\psi=0$ the variance by Eq. (2.2.7) becomes

$$
C(0)=c_{T} \mu^{2}
$$

and thus it follows that

$$
C\left(\psi_{0}\right)=\frac{1}{2} c_{T} \mu^{2}
$$

The solution with $\mu=0.99899012912$ (associated with $\psi_{0}=0.1^{\circ}$ ) is used in the software used for the computations. The constant $\mu$ is found from trivial iterations, see Eq. (2.2.8) and (2.2.10). Inserting $\mu$ into Eq. (2.2.9) $c_{T}$ is completely determined and $\sigma_{n}^{2}$ is then calculated. Pre-defined quantity $C(0)$ must be chosen from the user, as the accuracy of the gridded gravity anomalies. In our study we chose $C(0)=9 \mathrm{mGals}^{2}$. 


\subsection{Determination of the least-squares modification parameters}

To obtain the Least-Squares Modification (LSM) parameters, Eq. (2.1.10) is differentiated with respect to $s_{n}$, i.e., $\partial m_{\tilde{N}}^{2} / \partial s_{n}$. The resulting expression is then equated to zero, and the modification parameters $s_{n}$ are thus solved in the least-squares sense from the linear system of equations (Sjöberg 2003d):

$\sum_{r=2}^{L} a_{k r} s_{r}=h_{k}, k=2,3, \ldots . ., L$,

where

$a_{k r}=\sum_{n=2}^{\infty} E_{n k} E_{n r} C_{n}+\delta_{k r} C_{r}-E_{k r} C_{k}-E_{k r} C_{r}$,

and

$h_{k}=\Omega_{k}-Q_{k} C_{k}+\sum_{n=2}^{\infty}\left(Q_{n} C_{n}-\Omega_{k}\right) E_{n k}$

where

$\Omega_{k}=\frac{2 \sigma_{k}^{2}}{k-1}$

$\delta_{k r}= \begin{cases}1 & \text { if } k=r \\ 0 & \text { otherwise }\end{cases}$

$C_{k}=\sigma_{k}^{2}+ \begin{cases}c_{k} d c_{k} /\left(c_{k}+d c_{k}\right) & \text { if } 2 \leq k \leq M \\ c_{k} & \text { if } k>M\end{cases}$

$E_{n k}=\frac{2 k+1}{2} e_{n k}\left(\psi_{0}\right)$

and

$e_{n k}\left(\psi_{0}\right)=\int_{\psi^{0}}^{\pi} P_{n}(\cos \psi) P_{k}(\cos \psi) \sin \psi d \psi$

The modification parameters $s_{n}$ vary, depending on the quality of local gravity data, the chosen radius of integration $\left(\psi^{0}\right)$ and the characteristics of the GGM. The system of equations in Eq. (2.3.1) is usually so ill-conditioned that it cannot be solved by 
standard methods like Gaussian elimination. To overcome this problem, Ellmann (2005a) and Ågren (2004a) used the standard Singular Value Decomposition (SVD) procedure provided e.g. by Press et al. (1992). After the numerical solution of $s_{n}$, the corresponding coefficients $b_{n}$ are computed.

\subsection{Additive corrections in the KTH Approach}

In the determination of the geoid by Stokes' formula Eq. (2.1.4a), it is necessary that there are no masses outside the geoid and the gravity data should be reduced to the sea level. However, those criteria are not fulfilled, due to the presence of topography and atmospheric masses (forbidden masses) above the geoid surface. Hence, there are some necessary corrections that need to be added to the approximate geoidal height $\tilde{N}$.

In the KTH computational scheme for geoid determination (Sjöberg 2003c), the surface gravity anomalies and the GGM are used for the determination of $\tilde{N}$. After this, all necessary corrections are added to $\tilde{N}$. In contrast, in the classical approaches, these corrections are usually applied so that in the first step the surface gravity anomalies are corrected by removing the effects of topographic and atmospheric external masses or reducing them inside as a direct effect, and then, after applying Stokes' integral, their effects are restored (indirect effect). Besides, since the gravity anomalies in Stokes' formula must refer to the geoid to satisfy the second condition, a reduction of observed gravity from the Earth surface to the geoid is necessary. This step is called downward continuation (DWC). The computational procedure for estimation of the geoidal height $\hat{N}$ can be summarized by the following formula:

$\hat{N}=\tilde{N}+\delta N_{c o m b}^{T o p o}+\delta N_{D W C}+\delta N_{c o m b}^{a}+\delta N_{e}$

where $\delta N_{\text {comb }}^{\text {Topo }}$ is the combined topographic correction, which includes the sum of direct and indirect topographical effects, $\delta N_{D W C}$ is the downward continuation effect, $\delta N_{\text {comb }}^{a}$ is the combined atmospheric correction, which includes the sum of the direct 
and indirect atmospherical effects, and $\delta N_{e}$ is the ellipsoidal correction for the spherical approximation of the geoid in Stokes' formula to ellipsoidal reference surface.

\subsubsection{The Topographic Corrections}

The combined topographic effect is the sum of the direct and indirect effects, and can be added directly to the approximate geoidal height values as:

$$
\delta N_{\text {comb }}^{\text {Topo }}=\delta N_{\text {dir }}+\delta N_{\text {indir }} \approx-\frac{2 \pi G \rho}{\gamma} H^{2}
$$

where $\rho=2.67 \mathrm{~g} / \mathrm{cm}^{3}$ is the mean topographic mass density and $H$ is the orthometric height. This method is independent of the selected type of topographic reduction (Sjöberg 2000 and 2001a). On the other hand, the direct effect which is usually affected by a significant terrain effect, including possible lateral density variations, is cancelled in the combined topographic effect on the geoid.

Formula (2.4.1.1) is very simple and computer efficient. Because of the fact that rough surface gravity anomalies are integrated in the KTH approach, some important comments must be taken into account. As the gravity data is usually presented as surface blocks, an error occurs due to loss of short wavelength information (discretisation error) when estimating the mean anomalies $\Delta g$ from point gravity data. These errors can be reduced by using a special interpolation technique (Ågren 2004a and Kiamehr 2005). This technique uses a smoothing topographic correction that results in reduced gravity anomalies, which are smoother than the original ones. Then the observations are interpolated to a denser grid, and the topographic correction is finally restored, i.e. the masses are restored. The standard planar Bouguer or Residual Terrain Model (RTM) anomaly can be used in the interpolation stage. 


\subsubsection{The Downward Continuation Correction}

The analytical continuation of the surface gravity anomaly to the geoid is a necessary correction in the application of Stokes' formula for geoid estimation. This means that after the reduction of the topographic effect, the observed surface gravity anomalies must also be downward continued to the geoid. This correction is applied to the surface gravity anomalies in the classical approaches.

Traditionally, different methods are used for DWC, but using the inversion of Poisson's integral is the most common one. Sjöberg (2003a) designed a new method for the DWC of the full field gravity anomalies. In this method, the DWC effect is computed directly for the geoid height rather than for the gravity anomaly. In this case, the downward continuation effect is given by:

$\delta N_{D W C}=\frac{c}{2 \pi} \iint_{\sigma_{0}} S_{L}(\psi)\left(\Delta g^{*}-\Delta g\right) d \sigma$

where $\Delta g$ is the gravity anomaly at the surface computation point $\mathrm{P}$ and $\Delta g^{*}$ is the corresponding quantity downward continued to the geoid. The final formulas for Sjöberg's DWC method for any point of interest $P$ based on LSM parameters can be given by (for more details, see Ågren 2004):

$\delta N_{D W C}(P)=\delta N_{D W C}^{(1)}(P)+\delta N_{D W C}^{L 1, F a r}(P)+\delta N_{D W C}^{L 2}(P)$,

where

$\delta N_{D W C}^{(1)}(P)=H_{P}\left(\frac{\Delta g(P)}{\gamma}+3 \frac{N_{P}^{0}}{r_{P}}-\left.\frac{1}{2 \gamma} \frac{\partial \Delta g}{\partial r}\right|_{P} H_{P}\right)$,

and

$\delta N_{D W C}^{L 1, F a r}(P)=c \sum_{n=2}^{M}\left(s_{n}^{*}+Q_{n}^{L}\right)\left[\left(\frac{R}{r_{P}}\right)^{n+2}-1\right] \Delta g_{n}(P)$,

and 
$\delta N_{D W C}^{L 2}(P)=\frac{c}{2 \pi} \iint_{\sigma_{0}} S_{L}(\psi)\left(\left.\frac{\partial \Delta g}{\partial r}\right|_{P}\right)\left(H_{P}-H_{Q}\right) d \sigma_{Q}$,

where $r_{P}=R+H_{P}, \sigma_{0}$ is a spherical cap with radius $\psi$ centered around $P$ and it should be the same as in modified Stokes' formula, $H_{P}$ is the orthometric height of point $P$ and gravity gradient $\left.\frac{\partial \Delta g}{\partial r}\right|_{P}$ in point $P$ can be computed based on Heiskanen and Moritz (1967,p.115):

$\left.\frac{\partial \Delta g}{\partial r}\right|_{P}=\frac{R^{2}}{2 \pi} \iint_{\sigma_{0}} \frac{\Delta g_{Q}-\Delta g_{P}}{l_{0}^{3}} d \sigma_{Q}-\frac{2}{R} \Delta g(P)$

where $l_{o}=2 R \sin \frac{\psi_{P Q}}{2}$.

In Eq. (2.4.2.4) $\Delta g_{n}(P)=\frac{n-1}{R} \sum_{m=-n}^{n} A_{n m} Y_{n m}(P)$. Here $A_{n m}$ is the potential coefficient related to the fully normalized spherical harmonic (cf. Heiskanen and Moritz 1967,p. 31)

\subsubsection{The Atmospheric Correction}

As already mentioned, determination of the geoid by Stokes' formula, requires that there are no masses outside the geoid. This includes also the forbidden atmospheric masses outside the geoid surface. Their effect needs to be taken into account. It was emphasized by Sjöberg $(1998,1999 b, 2001 \mathrm{a}$ and 2006) that the application of the IAG approach using a limited cap size, and especially in the modified Stokes' formula, can cause a very significant error in the zero-order term (more than $3 \mathrm{~m}$ ). In the KTH scheme, the combined atmospheric effect $\delta N_{\text {comb }}^{a}$ can be approximated to order $H$ by (Sjöberg and Nahavandchi 2000) 


$$
\begin{aligned}
& \delta N_{\text {comb }}^{a}(P)=-\frac{2 \pi R \rho_{0}}{\gamma} \sum_{n=2}^{M}\left(\frac{2}{n-1}-s_{n}-Q_{n}^{L}\right) H_{n}(P) \\
& -\frac{2 \pi R \rho_{0}}{\gamma} \sum_{n=M+1}^{\infty}\left(\frac{2}{n-1}-\frac{n+2}{2 n+1} Q_{n}^{L}\right) H_{n}(P),
\end{aligned}
$$

where $\rho_{0}$ is the density at sea level radius $\rho^{0}\left(\rho^{0}=1.23 \times 10^{-3} \mathrm{~g} \mathrm{~cm}^{-3}\right)$ multiplied by the gravitational constant $G\left(G=6.673 \times 10^{-11} \mathrm{~m}^{3} \mathrm{~kg}^{-1} \mathrm{~s}^{-2}\right)$,

$\gamma$ is the mean normal gravity at sea level,

and $H_{n}$ is the Laplace harmonic of degree $n$ for the topographic height:

$$
H_{n}=\sum_{m=-n}^{n} H_{n m} \bar{Y}_{n m}
$$

The elevation $H$ of the arbitrary power $v$ can be presented to any surface point with latitude and longitude $(\varphi, \lambda)$ as:

$$
H^{v}(\varphi, \lambda)=\sum_{m=0}^{\infty} \sum_{m=-n}^{n} H_{n m}^{v} Y_{n m}(\varphi, \lambda)
$$

where $H_{n m}^{v}$ is the normalized spherical harmonic coefficient of degree $n$ and order $m$ that can be determined by the spherical harmonic analysis:

$$
H_{n m}^{v}=\frac{1}{4 \pi} \iint_{\sigma} H^{v}(\varphi, \lambda) Y_{n m}(\varphi, \lambda) d \sigma
$$

The normalized spherical harmonic coefficients $\left(H_{n m}^{v}\right)$ used in this study, were given by Fan (1998) and they were computed to degree and order 360.

\subsubsection{The Ellipsoidal Correction}


The well known Stokes formula determines the geoidal height from surface gravity anomalies on a sphere. As the Earths' shape is rather ellipsoidal with a flattening of the order of $1 / 300$, it can be expected that the error in Stokes' formula will also amount to this order, corresponding to an error of up to several decimetres of the geoidal height. In precise geoid determination, this spherical approximation should be taken into account by some correction term (ellipsoidal correction). Different authors have studied the ellipsoidal correction for the original Stokes formula through the years. The ellipsoidal correction for the original and modified Stokes formula is derived by Sjöberg (2003e) and Ellmann and Sjöberg (2004) in a series of spherical harmonics to the order of $e^{2}$, where $e$ is the first eccentricity of the reference ellipsoid.

The ellipsoidal correction can be estimated approximately by a simple formula (for more details, see Sjöberg 2004):

$\delta N_{e} \approx \psi_{0}^{o}\left[\left(0.12-0.38 \cos ^{2} \theta\right) \Delta g+0.17 \tilde{N} \sin ^{2} \theta\right]_{m m}$,

where $\psi_{0}^{o}$ is the cap size (in units of degree of arc), $\theta$ is geocentric co-latitude, $\Delta g$ is given in $\mathrm{mGal}$ and $\tilde{N}$ in $\mathrm{m}$.

Ellmann and Sjöberg (2004) concluded that the absolute range of the ellipsoidal correction in the least-squares modification of Stokes' formula does not exceed the $\mathrm{cm}$ level with a cap size within a few degrees. 


\section{Chapter 3}

\section{Construction and evaluation of the data bases}

\subsection{Construction of the gravity anomaly grid}

The gravity anomaly data base of Greece, which was provided by GETECH, included longitude, latitude, elevation, raw observed gravity, free air gravity and bouguer gravity anomaly information. The dataset contained 9335 points of terrestrial gravity measurements. For the purposes of this study, the gravity anomalies of Molodenskii were computed using the raw gravity measurements, the normal gravity $\gamma_{Q}$ on the reference ellipsoid and the elevation information of the points.

In the same way as the geoid and the reference ellipsoid are used in Stokes' theory, the earth surface and the telluroid are used by Molodenskii to describe the anomalous gravity field. Thus the gravity anomaly of Molodenskii is defined as the difference between the actual gravity on the earth surface and the normal gravity on the telluroid:

$\Delta g_{A}=g_{A}-\gamma_{\mathrm{B}}$

where point $A$ lies on the surface of the Earth and point $B$ along the ellipsoidal normal, at the telluroid. Numerically $\Delta g_{A}$ is close to the free air gravity anomaly on the geoid. If point $A$ has normal height $\mathrm{H}_{\mathrm{A}}$, then the normal gravity $\gamma_{B}$ on the telluroid can be calculated from the normal gravity $\gamma_{Q}$ on the ellipsoid:

$$
\gamma_{B}=\gamma_{Q}-2 \gamma_{e}\left(\frac{H_{A}}{a}\right)\left[1+f+m+\left(-3 f+\frac{5}{2} m\right) \sin ^{2} \phi\right]+3 \gamma_{e}\left(\frac{H_{A}}{a}\right)^{2}
$$

where $a$ is the equatorial radius, $\gamma_{e}$ the normal gravity at the equator (computed by Somigliana's formula), $f$ the geometric flattening of the reference ellipsoid, 
$m=\left(\omega^{2} a^{2} b\right) / G M=0.003449786000308$ (constant for GRS80) and $\varphi$ the geodetic latitude of the point.

The geoid models are strongly dependent on the quality and quantity of the gravity data entering into the solutions. Regardless of the effect of choosing a proper computational method for the determination of a geoid model, the quantity and quality of the gravity anomaly data base plays a major role in the final result.

Thus, before continuing to the construction of the grid, there were some tests performed to the data for gross error detection. The cross validation method, which was introduced by Geisser and Eddy (1979), was used for detection of outliers in the data. Cross validation calculates the $\Delta g$ value at a data point by using only values from the surrounding data points, omitting the value from the data point in question. Then the interpolation error is computed as:

Error $=$ interpolated value - observed value

The interpolated value was computed by using the mean value of the around the validated point. This procedure is used for validation of all data in the database. Points that are poorly estimated by surrounding data may be indicative of anomalous values. By drawing the histogram of the absolute values of differences between the interpolated and original gravity anomalies, one can easily find a sharp change of slope, which can indicate when, the residual values below this value should be true. This value can be used as a tolerance for detecting outliers. In this study, we used the Bouguer gravity anomalies for detection of outliers with the cross validation technique, because Bouguer gravity anomalies are 'smoother' than 'raw' gravity measurements or free-air gravity anomalies, thus it is easier to detect gross errors. 


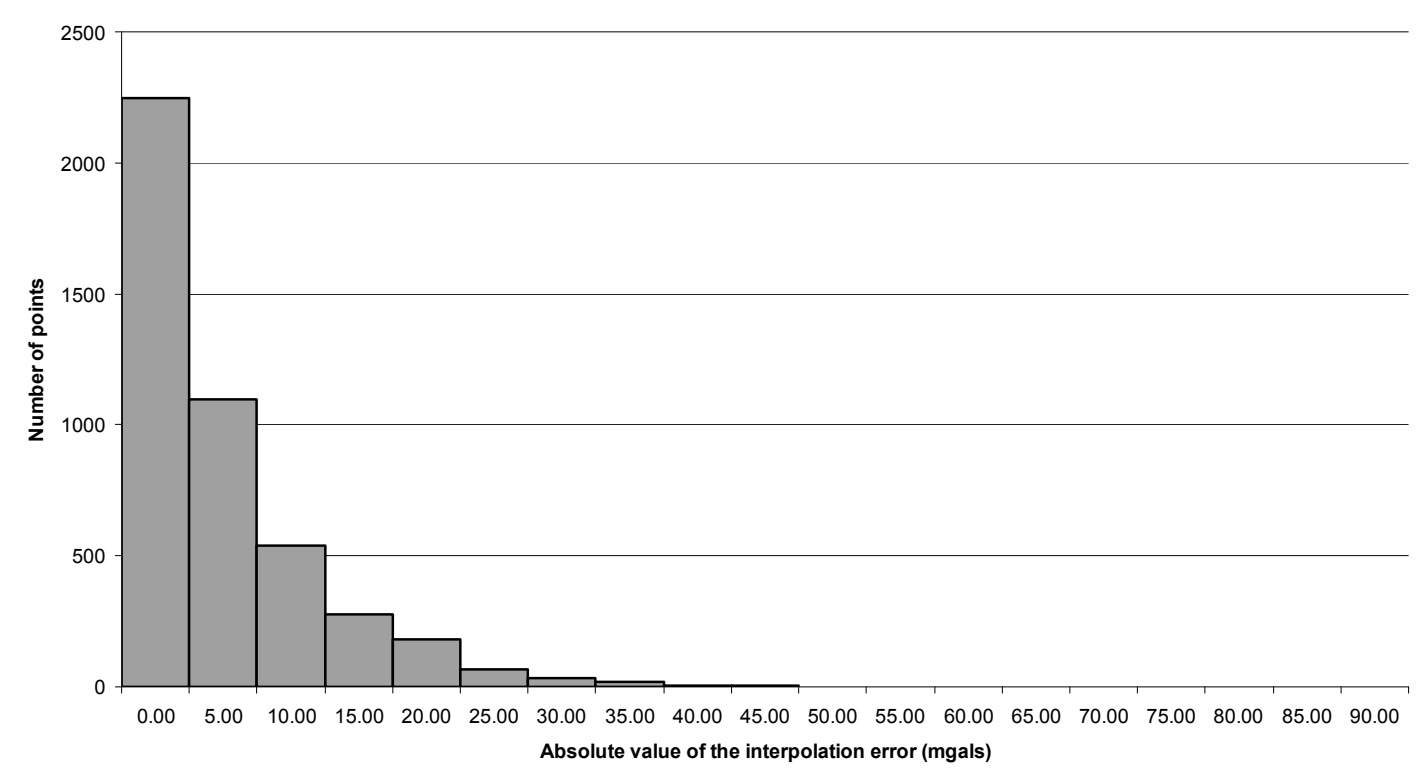

Fig. 3.1: Absolute values of the interpolation error of Bouguer gravity anomalies using cross validation technique

As it is shown in Fig. 3.1, most of the points have interpolation error smaller than 35 mGals, so this value was chosen as a tolerance above which, points were omitted from the dataset as outliers. From a total number of 9335 observation points, 87 points had interpolation error $>35 \mathrm{mGals}$ and are considered as outliers, thus leading to 9248 points in the dataset.

A second test for outlier detection was also performed, in which the gravity anomalies of Molodenskii were compared with free-air gravity anomalies computed by EGM96 global geopotential model. The absolute value of the differences is shown in Fig. 3.2. The results seem to be quite reasonable and the differences within the expected spectrum, so no data points were omitted as outlier. After all, the differences were expected to be large, as the GGM does not contain the high frequency information that the terrestrial data do. 


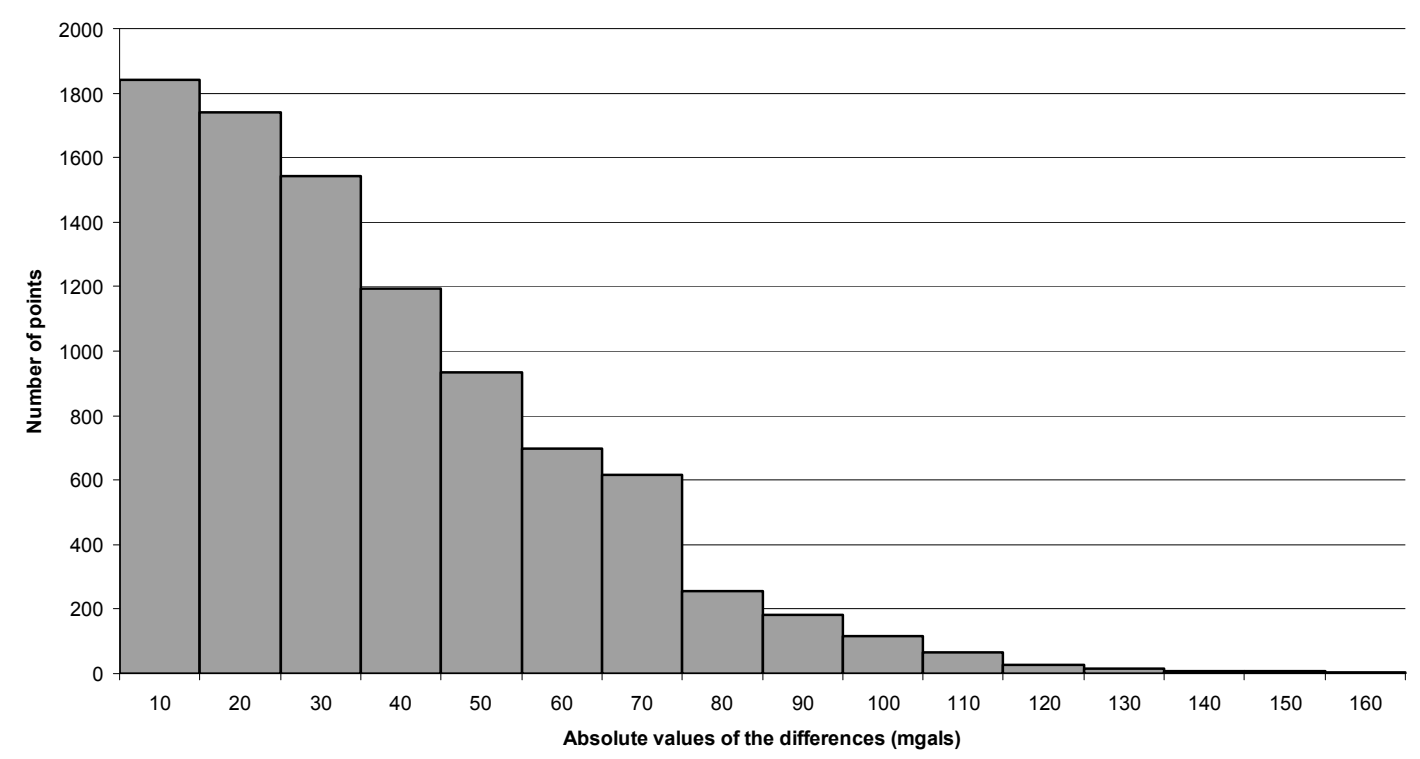

Fig. 3.2: Absolute values of the differences between the gravity anomalies of Molodenskii and the EGM96 free-air gravity anomalies.

A grid of $5^{\prime} \times 5^{\prime}$ resolution was chosen, according to the density of the gravity data. The South-West corner of the target area grid has $\varphi=34^{\circ} .50$ and $\lambda=19^{\circ} .50$ while the North-East has $\varphi=42^{\circ} .00$ and $\lambda=28^{\circ} .25$. The gravity anomaly value in each block was given by Kriging gridding algorithm, using the Linear variogram model (slope=1, anisotropy: ratio=1, angle=0). Kriging is the most frequently used method for prediction of gravity and geospatial data. It is a set of linear regression routines that minimize estimation variance from a predefined covariance model. A regionalized variable is intermediate between a truly random variable and a completely deterministic variable in the sense that it varies in a continuous manner from one location to the next. Therefore, points that are located near each other have a certain degree of spatial correlation, but points that are widely separated are statistically independent. The results used in this study for gridding of data with Kriging algorithm were produced using SURFER software produced by Golden Software Inc., Colorado.

For the scope of this study, the grid was extended beyond the target area in an offset of $3^{\circ}$, as the integration for each computation point is truncated at the fixed spherical 
distance $\psi_{o}=3^{\circ}$. Fig. 3.3 shows the borders of the target area and the outer borders at the fixed spherical distance of $3^{\circ}$. The constructed grid contained blocks with no gravity information inside. Thus in order to obtain a consistent anomaly grid, the freeair anomalies for data gaps were computed from EGM96, using formula (2.1.4b).

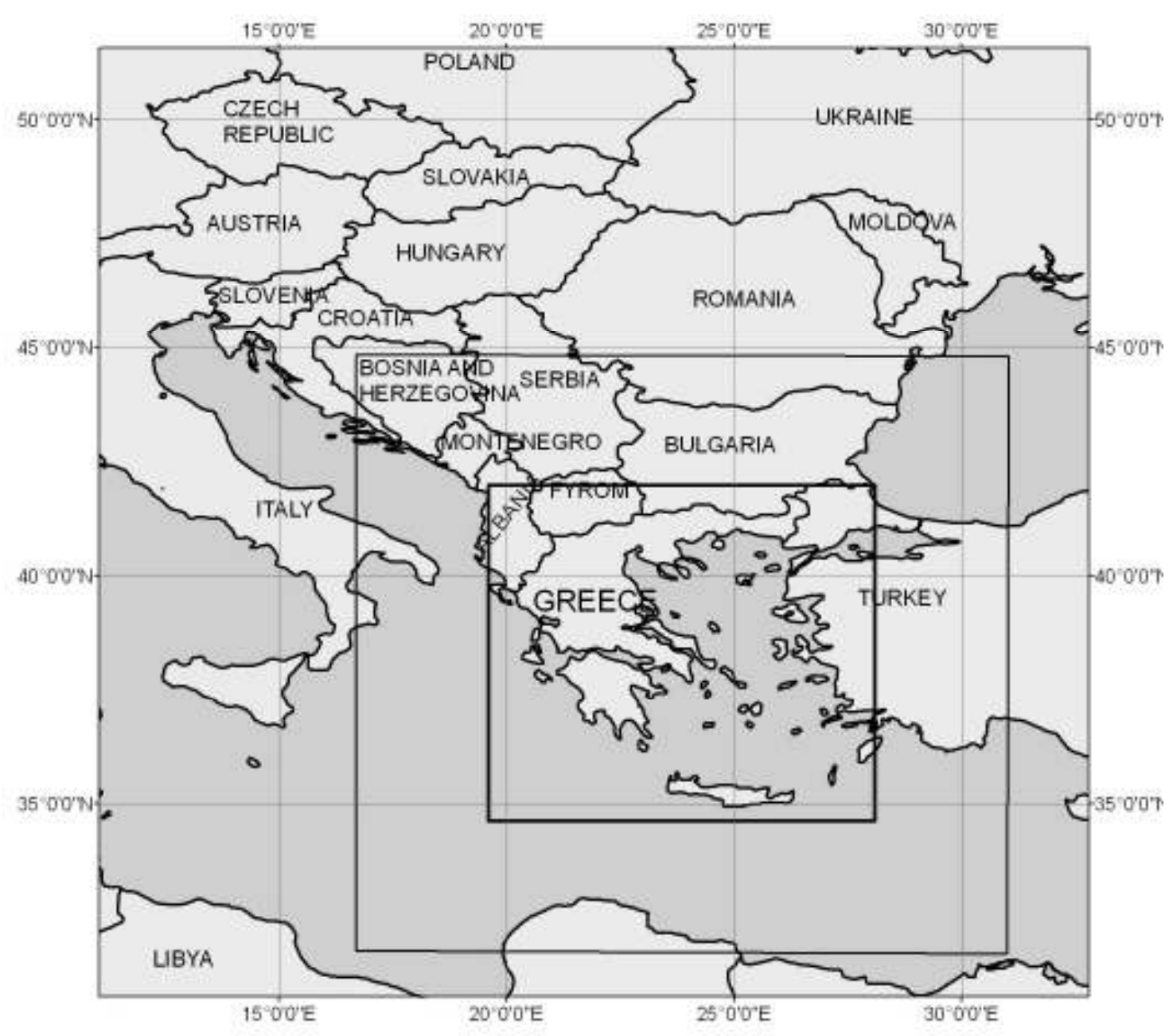

Fig. 3.3: Location of the target area is enclosed by the smaller/bold rectangle. External rectangle encloses the target area at a spherical distance of $3^{\circ}$ degrees from its borders.

It can be noticed, in Fig. 3.3, that the limited extension of the terrestrial data is a serious restriction to this study. There are many computational points that used blocks with EGM96 free-air gravity anomaly value, during the modified Stokes integration. Fig. 3.4 shows the density of the gravity measurements for a grid of $1^{0} \times 1^{0}$ block size. 


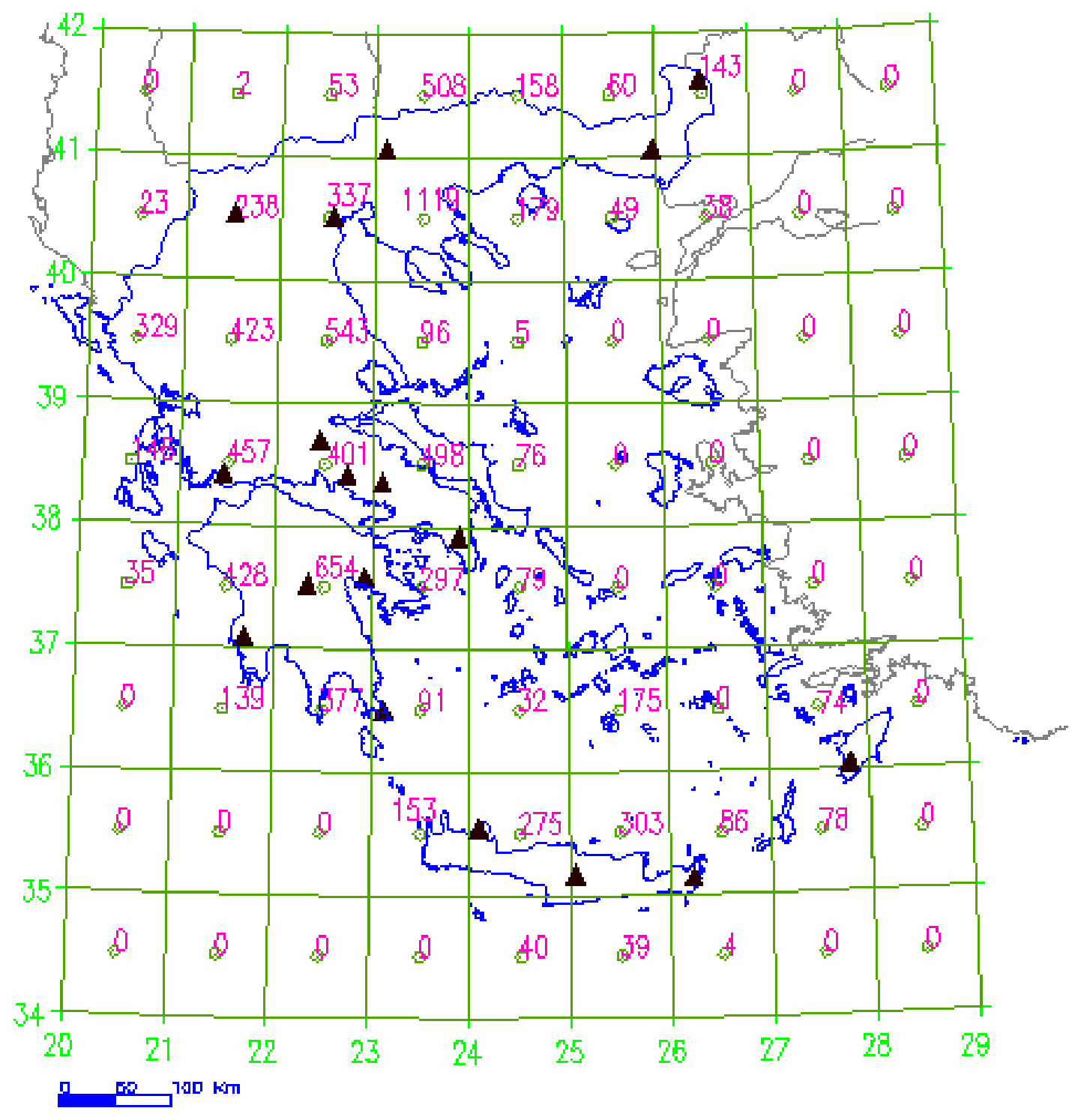

Fig. 3.4: Density of gravity measurements in a $1^{0} \times 1^{0}$ grid. Each block shows the number of the gravity data points that were included in the block. The GPS/levelling points used in the evaluation are also shown. 


\subsection{The Digital Elevation Model}

The Digital Elevation Model (DEM) used in this study was provided by the National Technical University of Athens (NTUA). The DEM had a resolution of $250 \times 250 \mathrm{~m}$ and was extended at the region of $18^{\circ} .6 \leq \lambda \leq 29^{\circ} .5$ and $34^{\circ} \leq \varphi \leq 42^{\circ}$. The DEM was then resampled in a $5^{\prime} \times 5^{\prime}$ grid, covering our target area $19^{\circ} .5 \leq \lambda \leq 28^{\circ} .25$ and $34^{\circ} .5 \leq \varphi \leq 42^{\circ}$. The Greek DEM was formatted by combining information from:

- $1 / 500000$ elevation isolines maps of Greece

- Greek geodetic network of orders $(I-I V)$

- $1 / 250000$ coastline maps of Greece

- $1 / 1000000$ ocean depth isoline maps

- Numerous points of bathymetric measurements 


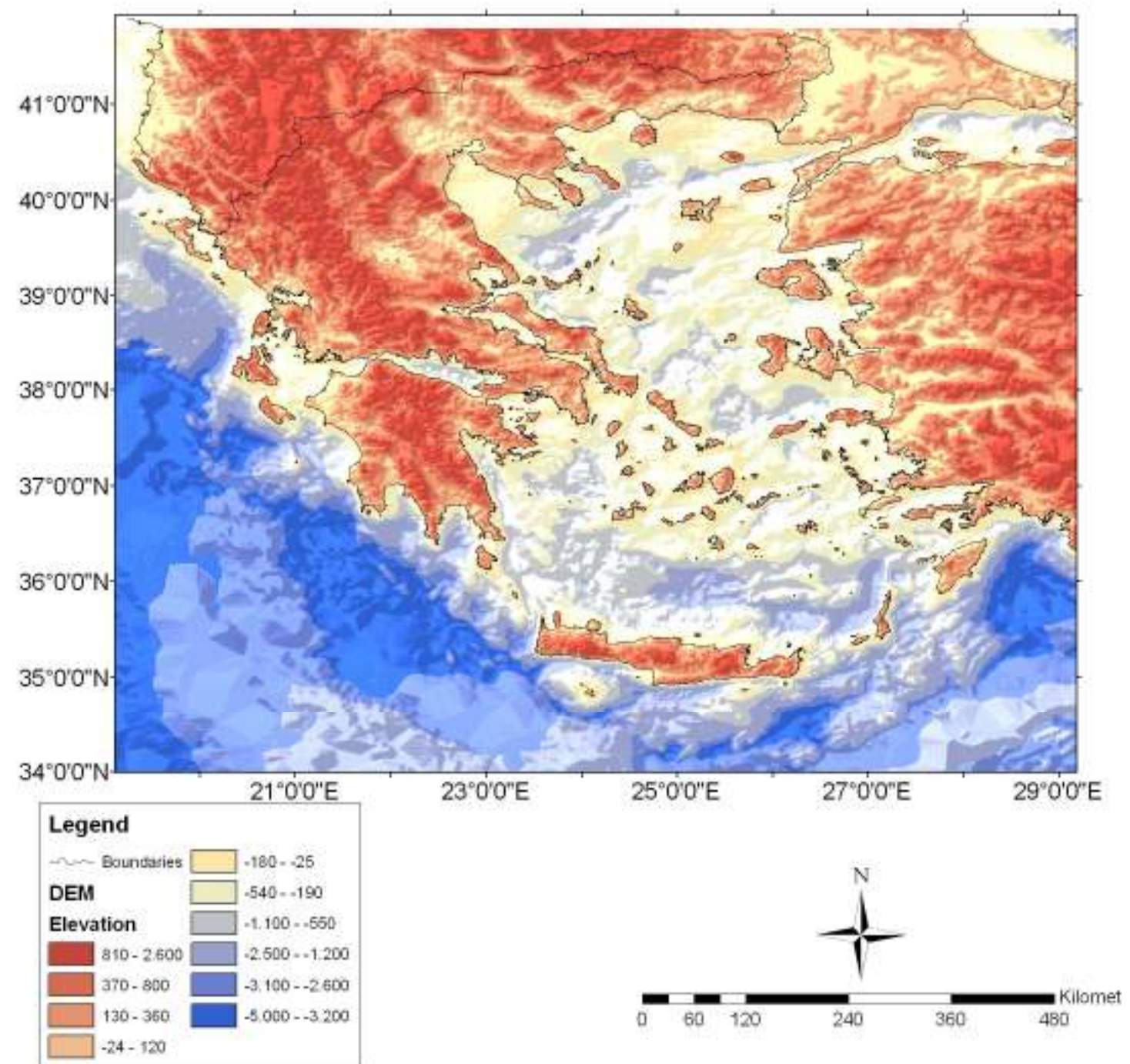

Fig. 3.5: The $250 \times 250 m$ DEM of Greece. 


\subsection{The GPS/Levelling Data}

The GPS/Levelling points were provided from the National Technical University of Athens (NTUA), and they all belong to the Greek geodetic network, varying from $1^{\text {st }}$ to $4^{\text {th }}$ order. The points were chosen in a way that they were well distributed inside the Greek region. The geodetic coordinates of the points were derived from GPS measurements performed for different projects of NTUA, merely for tectonic motion research. Unfortunately there are many inconsistencies to the way the coordinates of those points were computed, like datum and epoch discrepancies, tectonic motion and general geodynamic effects not considered in the solution. Concerning the orthometric heights of the points, they were taken from the Greek geodetic network, but the measuring method varied from spirit to trigonometric levelling. The exact time period of the GPS observations is also unknown, varying from 4 to 9 hours.

The GPS mean standard deviation of the ellipsoidal heights is estimated to approximately $\sigma_{h} \approx \pm 10 \mathrm{~cm}$ while the absolute accuracy of the orthometric heights to $\sigma_{H} \approx \pm 20 \mathrm{~cm}$

Table 3.1 shows the coordinates of the GPS/levelling points used for the evaluation of the geoid model as well as their orthometric and geoid height values. 
Table 3.1: Coordinates of the GPS/levelling points used for the evaluation. The orthometric and geoid height values are also shown.

\begin{tabular}{|c|c|c|c|c|c|c|c|}
\hline Nr & Name & Order & $\mathbf{f}(\mathbf{d e g})$ & $\mathbf{l}(\mathbf{d e g})$ & $\mathbf{h}(\mathbf{m})$ & $\mathbf{H}$ orth (m) & $\boldsymbol{N}_{\text {GPS/Levelling }}(\boldsymbol{m})$ \\
\hline 1 & STRN & I & 41.594526675 & 26.451127683 & 174.793 & 134.960 & 39.833 \\
2 & ELNK & I & 41.013625809 & 23.111816628 & $1,024.959$ & 982.084 & 42.875 \\
3 & KOLI & IV & 40.478645295 & 22.455576618 & 427.247 & 386.570 & 40.677 \\
4 & 335080 & IV & 40.472679011 & 21.509602976 & $1,636.667$ & 1595.462 & 41.205 \\
5 & AS76 & IV & 38.674366472 & 22.441055494 & 465.138 & 430.243 & 34.895 \\
6 & CS688 & IV & 38.411691909 & 22.735363599 & 724.256 & 688.768 & 35.488 \\
7 & THOM & IV & 38.391995780 & 21.487735238 & 152.91 & 127.128 & 25.782 \\
8 & VA64 & IV & 38.378538656 & 23.087984289 & 202.033 & 165.290 & 36.743 \\
9 & KRPI & IV & 37.904186795 & 23.834570617 & 293.69 & 255.298 & 38.392 \\
10 & MARA & IV & 37.555944284 & 22.925491362 & 301.477 & 267.965 & 33.512 \\
11 & TR953 & IV & 37.530772602 & 22.356252867 & 984.793 & 953.830 & 30.964 \\
12 & PTRF & IV & 37.079643619 & 21.689125222 & 430.633 & 406.120 & 24.513 \\
13 & SKLO & IV & 35.517721941 & 24.080134741 & 224.799 & 201.910 & 22.889 \\
14 & OXKF & II & 35.119832768 & 25.079518341 & 830.747 & 808.640 & 22.107 \\
15 & KRFL & I & 41.044222708 & 25.888467605 & 890.368 & 849.459 & 40.910 \\
16 & PLI & IV & 36.512760193 & 23.093738158 & 575.065 & 548.031 & 27.034 \\
17 & ZAK2 & IV & 35.127061735 & 26.208653130 & 565.145 & 547.623 & 17.522 \\
18 & SKDI & I & 36.020881556 & 27.805446730 & 583.714 & 563.164 & 20.550 \\
\hline
\end{tabular}




\section{Chapter 4}

\section{Geoid computation}

\subsection{Numerical evaluation of Stokes' formula}

The grid method was used for numerically integrating the surface integrals for geoid determination. The first part of the geoid estimator in equation (2.1.4a) will change in the following way, considering the grid that was constructed for the area:

$$
\begin{aligned}
& \tilde{N}_{1}=\frac{c}{2 \pi} \iint_{\sigma_{o}} \Delta g S^{L}(\psi) d \sigma=\frac{c}{2 \pi} \sum_{i} \sum_{j} \iint_{\sigma_{i j}} \Delta g S^{L}(\psi) d \sigma_{i j} \\
& \approx \frac{c}{2 \pi} \sum_{i} \sum_{j} \iint_{\sigma_{i j}} \Delta \bar{g}_{i j} S^{L}\left(\psi_{i j}\right) d \sigma_{i j}=\frac{c}{2 \pi} \sum_{i} \sum_{j} \Delta \bar{g}_{i j} S^{L}\left(\psi_{i j}\right) \iint_{\sigma_{i j}} d \sigma_{i j} \\
& =\frac{c}{2 \pi} \sum_{i} \sum_{j} \Delta \bar{g}_{i j} S^{L}\left(\psi_{i j}\right) \iint_{\sigma_{i j}} d \sigma_{i j}=\frac{c}{2 \pi} \sum_{i} \sum_{j} \Delta \bar{g}_{i j} S^{L}\left(\psi_{i j}\right) A_{i j}
\end{aligned}
$$

where, $\psi_{i j}$ is the spherical distance from the computation point $(\varphi, \lambda)$ to the block center of $\sigma_{i j}$ and $A_{i j}$ is the area of the block $\sigma_{i j}$. The spherical distance $\psi_{i j}$ can be computed by the following formula:

$\cos \psi_{i j}=\sin \varphi \sin \varphi_{i}+\cos \varphi \cos \varphi_{i} \cos \left(\lambda-\lambda_{j}\right)$

where $\varphi, \lambda$ and $\varphi_{i}, \lambda_{j}$ are the latitude and the longitude of the computation point and the block center respectively.

The area of each block $A_{i j}$ can be computed as follows:

$$
A_{i j}=\iint_{\sigma_{i j}} d \sigma=2 \Delta \lambda \sin (\Delta \varphi / 2) \cos \varphi_{i}
$$




\subsection{Computational aspects}

In this study, the program LS.coeff.m of Dr Artu Ellman has been used to compute the core quantities of stochastically modified Stokes's formula. Seven computation subroutines are associated with LS.coeff.m, namely sigma_terr_1.m, ggm_degree_variances_2.m, trunc_coeff_3.m, tsvd_4.m, ttls_5.m, BN_boeff_plot_6.m, modif_kernel_7.m (Ellmann 2005a). The program and its subroutines provided the $s_{n}$ and $b_{n}$ LS coefficients as long as some useful figures. The LS coefficients were then used by the authors' own programs for computing the approximate geoidal height $\tilde{N}$ as explained in previous chapters. Choosing the proper GGM and modification parameter is an essential step in the determination of the geoid model using the LSMS formula.

\subsubsection{Geopotential models}

For the choice of the best GGM in the combined solution of the LSMS formula, three GGMs have been tested: The EGM96, EIGEN-GRACE02S and EIGEN-GL04C models. The EGM96 model is a composite solution with harmonic coefficients complete to degree and order 360 . It consists of a combination solution to degree and order 70, a block diagonal solution from degree 71 to 359 , and a quadrature solution at degree 360. The combination model is based on satellite tracking data to over 20 satellites, including those tracked by Satellite Laser Ranging (SLR), GPS, the Tracking Data Relay Satellite System (TDRSS) and Tranet Doppler, direct altimetry from TOPEX, ERS-1, and GEOSAT, as well as the normal equations of the $1^{\circ} \times 1^{\circ}$ surface gravity data (excluding the altimeter derived anomalies) to degree and order 70 . The quadrature solution is based on the satellite only counterpart of EGM96 (EGM96S), as well as the surface gravity data and altimeter derived anomalies described above. The block diagonal solution is also built on EGM96S, and uses the same 30'x30' data, and in addition uses the quadrature solution as a reference. The spatial resolution of the "satellite-only" solution is limited to about $600-700 \mathrm{~km}$, implying the highest harmonic degree as of 36. Medium and short wavelengths are derived from the satellite altimetry, terrestrial, marine or airborne gravity data - of varying epoch, quality and 
geographic coverage. The accuracy of the EGM96 at the higher degrees is quite dependent on the geographic coverage of gravity data that go into the solution.

The GRACE is a dedicated satellite mission whose objective is to map the global gravity field with unprecedented accuracy over a spatial range from $400 \mathrm{~km}$ to 40,000 $\mathrm{km}$ every 30 days. The two GRACE satellites, jointly managed by National Aeronautics and Space Administration (NASA) and Deutsches Zentrum für Luft- und Raumfahrt (DLR) were launched on March 17, 2002 in a near-circular orbit at about $500 \mathrm{~km}$ altitude. They are separated from each other by approximately $220 \mathrm{~km}$ alongtrack, and this distance and its rate of change (accuracy: $10^{-3} \mathrm{~mm} / \mathrm{sec}$ ) are measured using a K-band microwave ranging system. The instrumentation allows for continuous GPS-GRACE high-low satellite-to-satellite tracking, on-board measurement of nongravitational accelerations, precise attitude determination, and - being the most important component - the observation of the inter-satellite distance and its rate of change.

GRACE satellite-only Earth gravity field model EIGEN-GRACE02S is complete to degree and order 150 and was released on February 13, 2004 to the GRACE Science Team and August 9, 2004 to the public. The solution for EIGEN-GRACE02S model has been derived solely from satellite orbit perturbations and is independent from oceanic and continental surface gravity data. This criterion is important for our study since it allows us to apply standard stochastic models without "tailoring" the GGMrelated errors after the area of interest. EIGEN-GRACE02S model resolves the geoid with an accuracy of better than $1 \mathrm{~mm}$ at a resolution of $1000 \mathrm{~km}$ half-wavelength is about one order of magnitude more accurate than recent CHAMP derived global gravity models and more than two orders of magnitude more accurate than the latest pre-CHAMP satellite-only gravity models. The model is complete to degree and order 150 , but it provides full power almost up to degree 120 .

The recent improvements in the GRACE tracking data processing and the availability of newer surface gravity data sets in the Arctic, Antarctica and North-America, and the availability of a new mean sea surface height model from altimetry processing at GeoForschungsZentrum Potsdam (GFZ) gave rise to the generation of two new global 
gravity field models. The first one was the EIGEN-GL04S1 and the second one the EIGEN-GL04C model. EIGEN-GL04C model, which was used in this study, is an upgrade of EIGEN-CG03C model. It is a combination of GRACE and LAGEOS missions plus $0.5^{\circ} \times 0.5^{\circ}$ gravimetry and altimetric surface data and it is complete to degree and order 360 thus it resolves geoid and gravity anomalies at half wavelengths of $55 \mathrm{~km}$ at the equator. A degree-dependent combination method has been applied in order to preserve the high accuracy from the GRACE satellite data in the lower frequency band of the geopotential and to form a smooth transition to the highfrequency information coming from the surface data.

\subsubsection{Modification limits}

The selection of the upper limit of the geopotential model, $M$, and the upper limit of the harmonics to be modified in Stokes's function, $L$, are of crucial importance in the geoid modeling. The choice of the upper limit $M$ of the GGM is directly related to the quality of the GGM to be used. In practice, due to restricted access to terrestrial data the integration radius $\psi_{0}$ is often limited to a few hundred kilometres. This implies that a relative high $M$ should counterbalance this limitation. On the other hand, the GGM error grows with increasing degree, so there must be a compromise between those two aspects for choosing the best value for $M$. In this study, the optimum (Sjöberg 2003d) LS modification method is implemented, which assumes that the upper bound of the harmonics to be modified in Stokes's function, $L$, is at least as high as $M$, i.e. $L \geq M$. In our case it is $L=M$.

In all GGM tested the same choice for the size of the moving integration cap with "fixed" radius $\psi_{0}=3^{0}$ was made. Table 4.1 summarizes the input parameters that were chosen while computing the $s_{n}$ and $b_{n}$ LS parameters with LScoeff.m program with the different GGM used each time. 
Table 4.1: Input parameters that were chosen for computing the $s_{n}$ and $b_{n}$ LS parameters with LScoeff.m program.

\begin{tabular}{|c|c|c|c|}
\hline & EIGEN-GRACE02S & EGM96 & EIGEN-GL04C \\
\hline $\mathrm{M}=\mathrm{L}$ & 120 & 360 & 360 \\
\hline$\psi_{0}$ & $3^{0}$ & $3^{0}$ & $3^{0}$ \\
\hline$\sigma_{\Delta g}$ & $9 \mathrm{mGal}$ & $9 \mathrm{mGal}$ & $9 \mathrm{mGal}$ \\
\hline
\end{tabular}

Due to the fact that the unbiased and optimum methods yield ill-conditioned systems (condition number of the $A$ matrix ranges fromcond(A) $=10^{15}$ to $10^{18}$ ) program LScoeff.m uses some Singular Value Decomposition (SVD) methods for solving those problems (more details in Ellman-2005a). One useful remark that the SVD was performed successfully is that the unbiased/optimum $b_{n}$ shouldn't deviate too much (say more than $10^{-2}$ ) from the biased solution (where $s_{n}=b_{n}$ ). In this case the regularization results would be meaningless and some different truncation limits $k$ should be chosen. At the same time the residual norm $\left(\|A s-h\|_{2}\right)$ of the final parameters to be used in geoid modelling is recommended to remain less than $10^{-12}$. While executing the program, the user chooses the regularization parameter that thinks it's the best, judging from the tables with values such as the residual norm and the global mean square error (which obviously should be as small as possible) that appear in the meantime. In this study all those values were in the "safe" spectrum and the SVD technique was performed successfully.

Furthermore the typical behaviour of $S^{L}(\psi)$ across the integration cap is also investigated (by sub-routine modif_kernel7.m). Importantly, any LS parameters set "forces" the modified Stokes function to zero (approximately) at the edge of the integration cap. Convergence of $S^{L}(\psi)$ to zero at the edge of the integration cap is a useful feature, which is directly associated with the minimization of the truncation bias. Fig. 4.1, Fig 4.2 and Fig 4.3 show the way that the original Stokes function $S(\psi)$ and the modified Stokes function $S^{L}(\psi)$ behave in respect to the spherical distance $\left(\psi_{0}\right)$ for EGM96, EIGEN-GL04C and EIGEN-GRACE02S model respectively. 


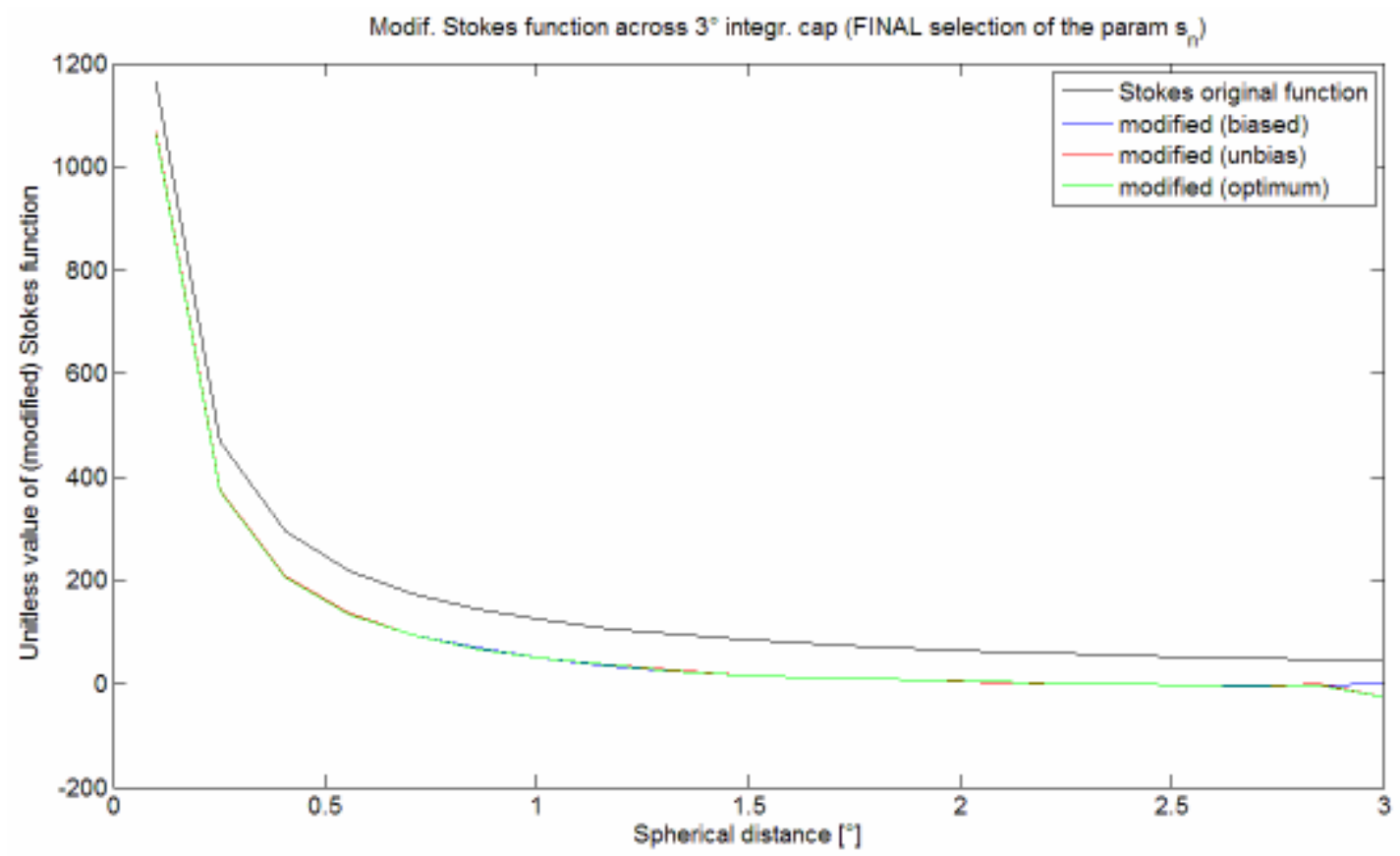

Fig. 4.1: Behavior of the LS modified Stokes function $S^{L}(\psi)$ for EGM96 model with modification degree $\mathrm{M}=\mathrm{L}=360$ and cap size $\psi_{0}=3^{0}$

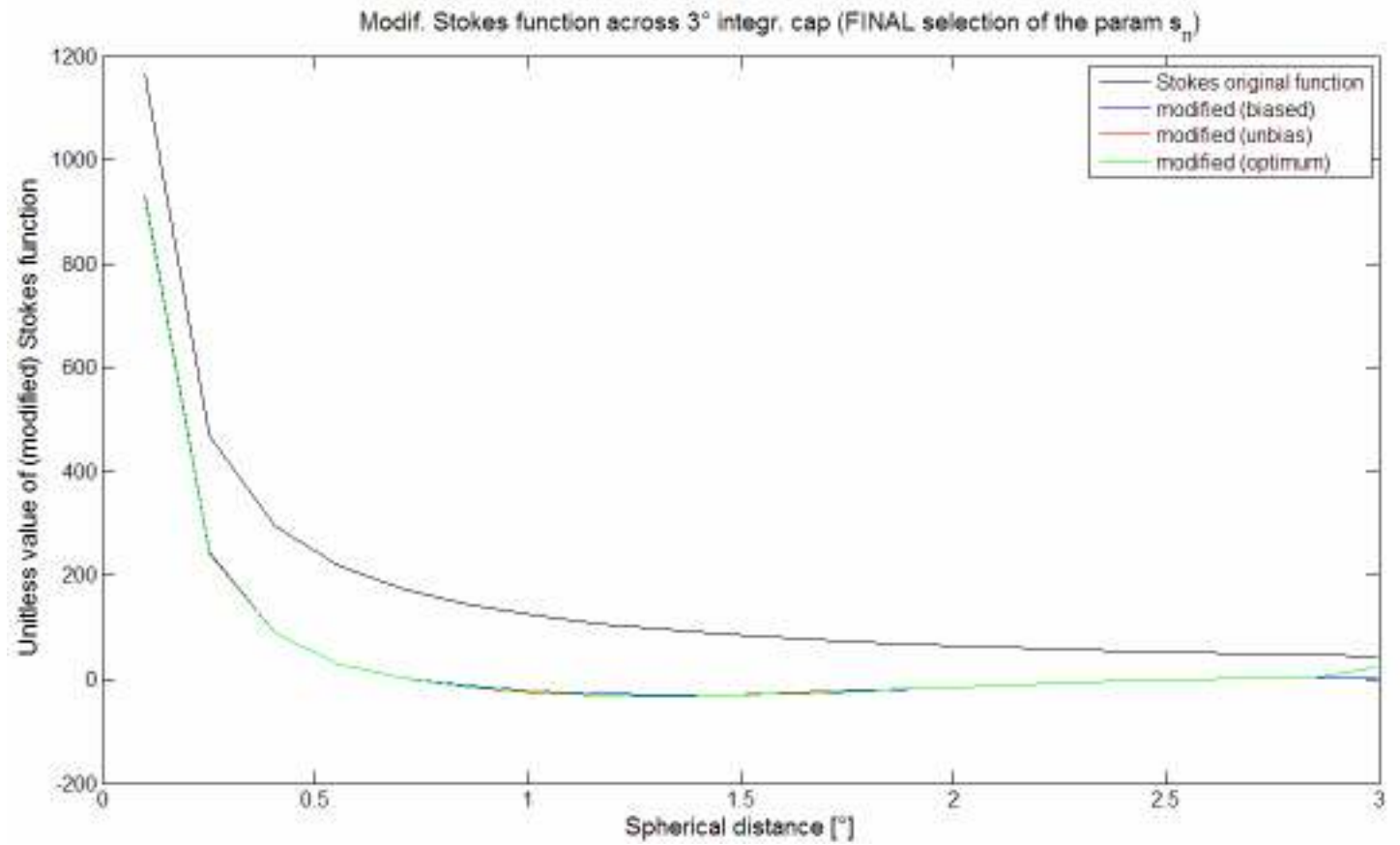

Fig. 4.2: Behavior of the LS modified Stokes function $S^{L}(\psi)$ for EIGEN-GL04C model with modification degree $M=L=360$ and cap size $\psi_{0}=3^{\circ}$ 


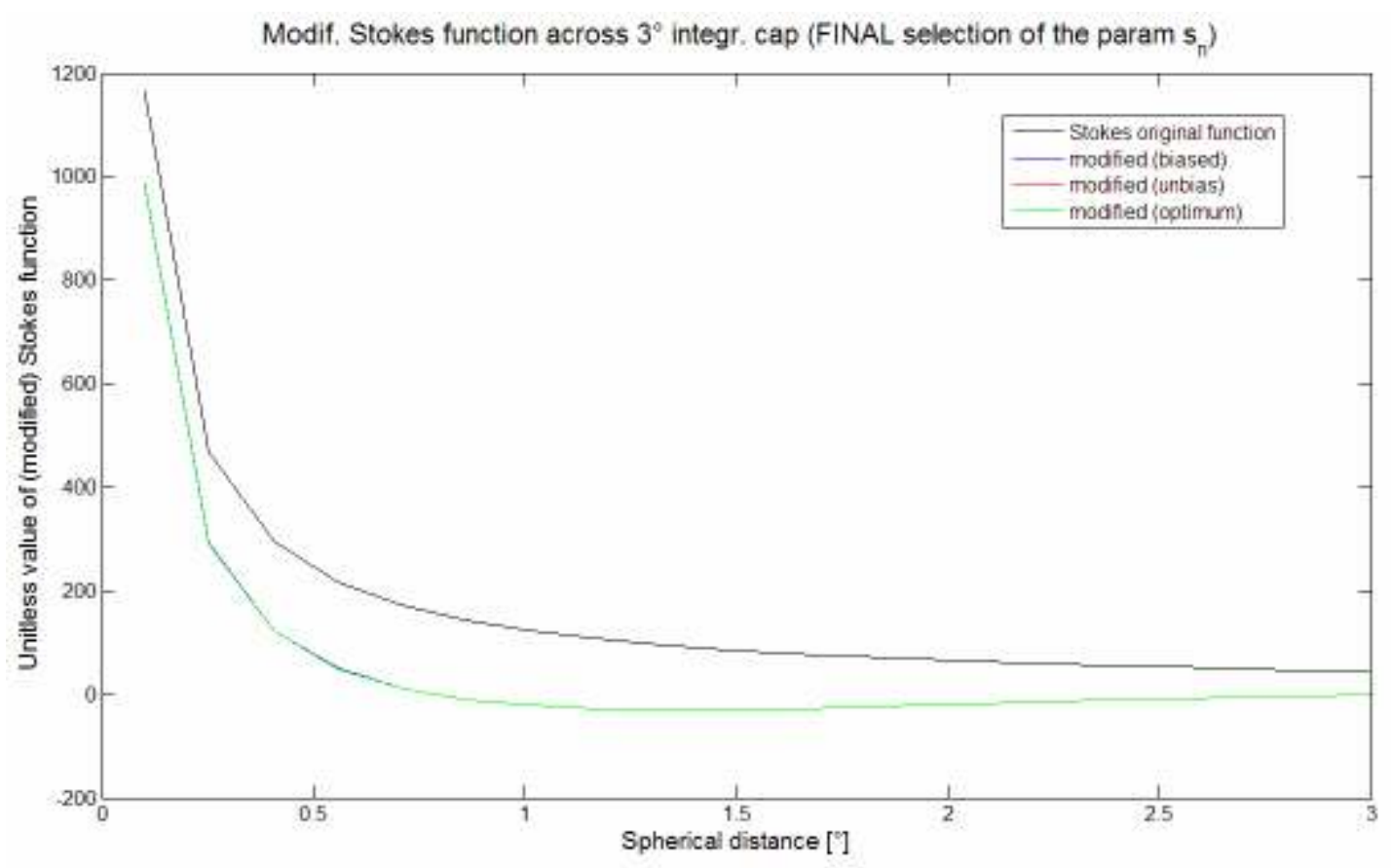

Fig. 4.3: Behavior of the LS modified Stokes function $S^{L}(\psi)$ for EIGEN-GRACE02S model with modification degree $M=L=120$ and cap size $\psi_{0}=3^{\circ}$

By inspecting Fig. 4.1, Fig 4.2, one can notice that for EGM96 and EIGEN-GL04C model the LS modified Stokes's function $S^{L}(\psi)$ does not converge to zero at the edge of the integration cap for the optimum solution, which means that there is still a truncation bias left. On the other hand, Fig 4.3 shows that for EIGEN-GRACE02S model $S^{L}\left(\psi_{0}\right) \approx 0$, meaning that the LS modified Stokes's function converges to zero at the edge of the cap $\left(\psi_{0}=3^{\circ}\right)$, which is directly associated with the minimization of the truncation bias. This is also a reason for choosing the EIGEN-GRACE02S model for the final geoid computations. 


\subsection{The New Gravimetric Geoid Model}

In this chapter, the final geoid model is presented, along with the necessary corrections that were computed for the KTH scheme. The DWC correction was not included in the additive corrections for estimating the precise geoidal undulations. The reason was that the DEM model in our disposal was not as extended as $\delta N_{D W C}^{L 2}$ correction in Eq. (2.4.2.5) required. This correction required DEM values over an area $\sigma_{0}$ captured by a spherical cap of $\psi_{0}=3^{0}$, meaning that DEM values are also needed for the extended region enclosed in the outer rectangle in Fig. 3.3, criterion that was not fulfilled. Hence, the formula used in this study for computing the precise geoid values is:

$$
\hat{N}=\tilde{N}+\delta N_{c o m b}^{T o p o}+\delta N_{c o m b}^{a}+\delta N_{e}
$$

The additive corrections are shown below in Fig. 4.4, Fig. 4.5 and Fig. 4.6 and the final gravimetric geoid model for Greece is shown in Fig 4.7.

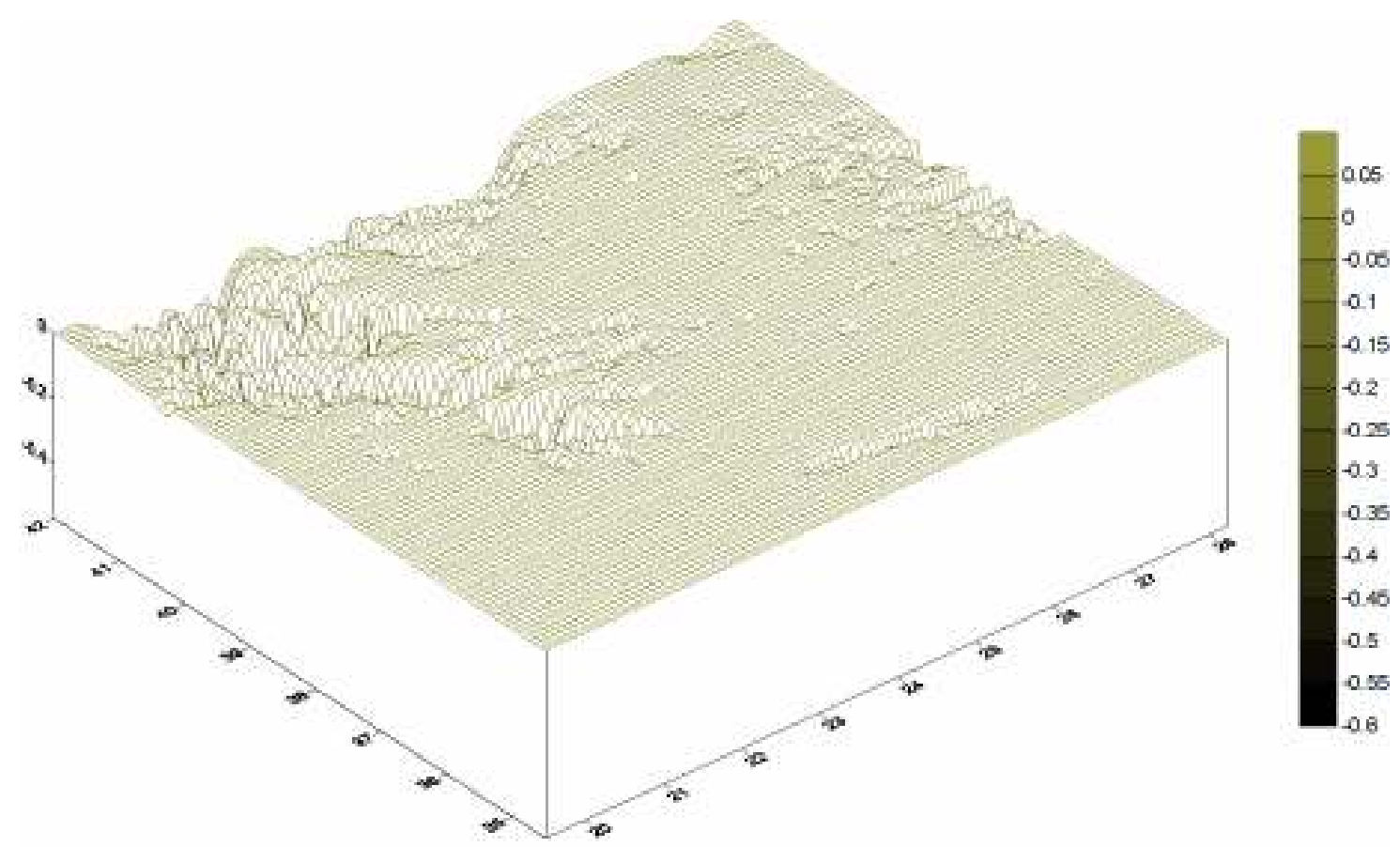

Fig. 4.4: Combined topographic effect for the new Greek gravimetric geoid model. Unit: $\mathrm{m}$ 


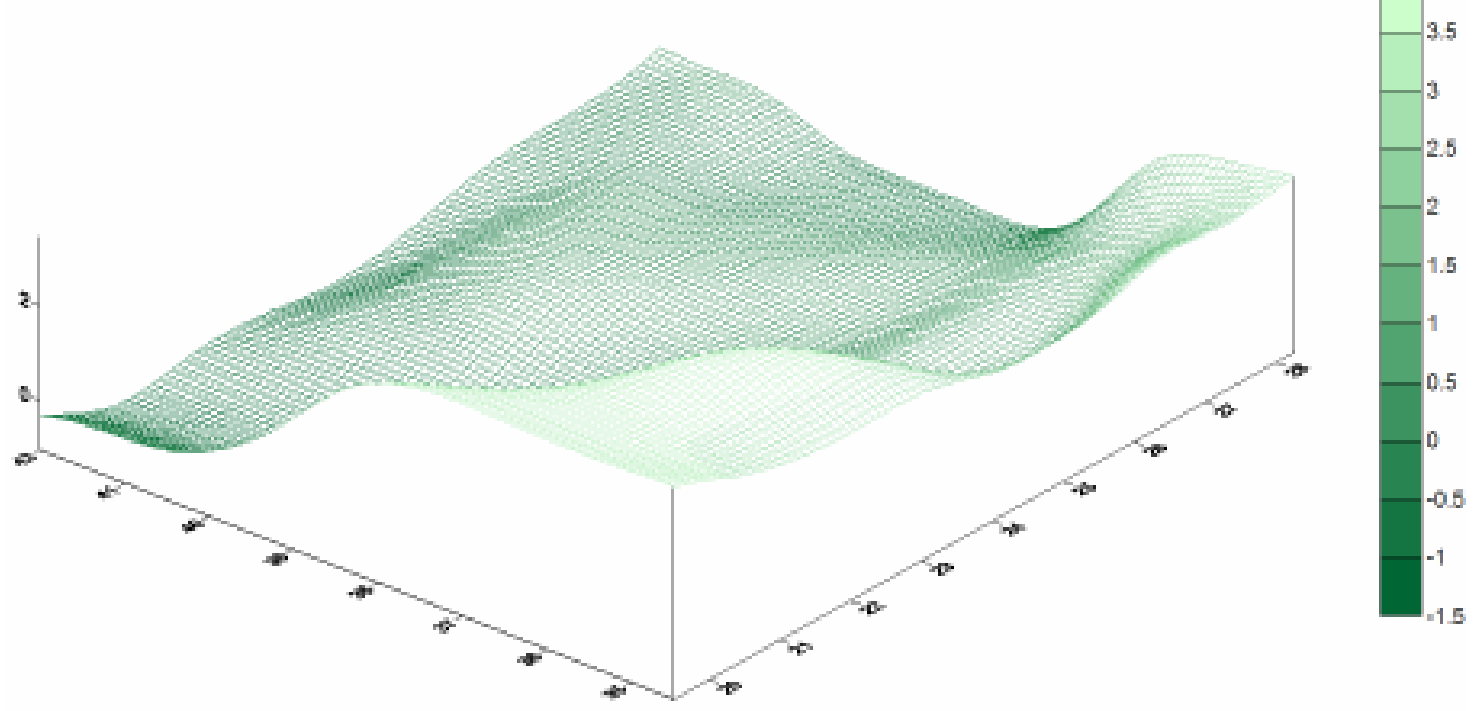

Fig. 4.5: Ellipsoidal correction for the new Greek gravimetric geoid model. Unit: mm

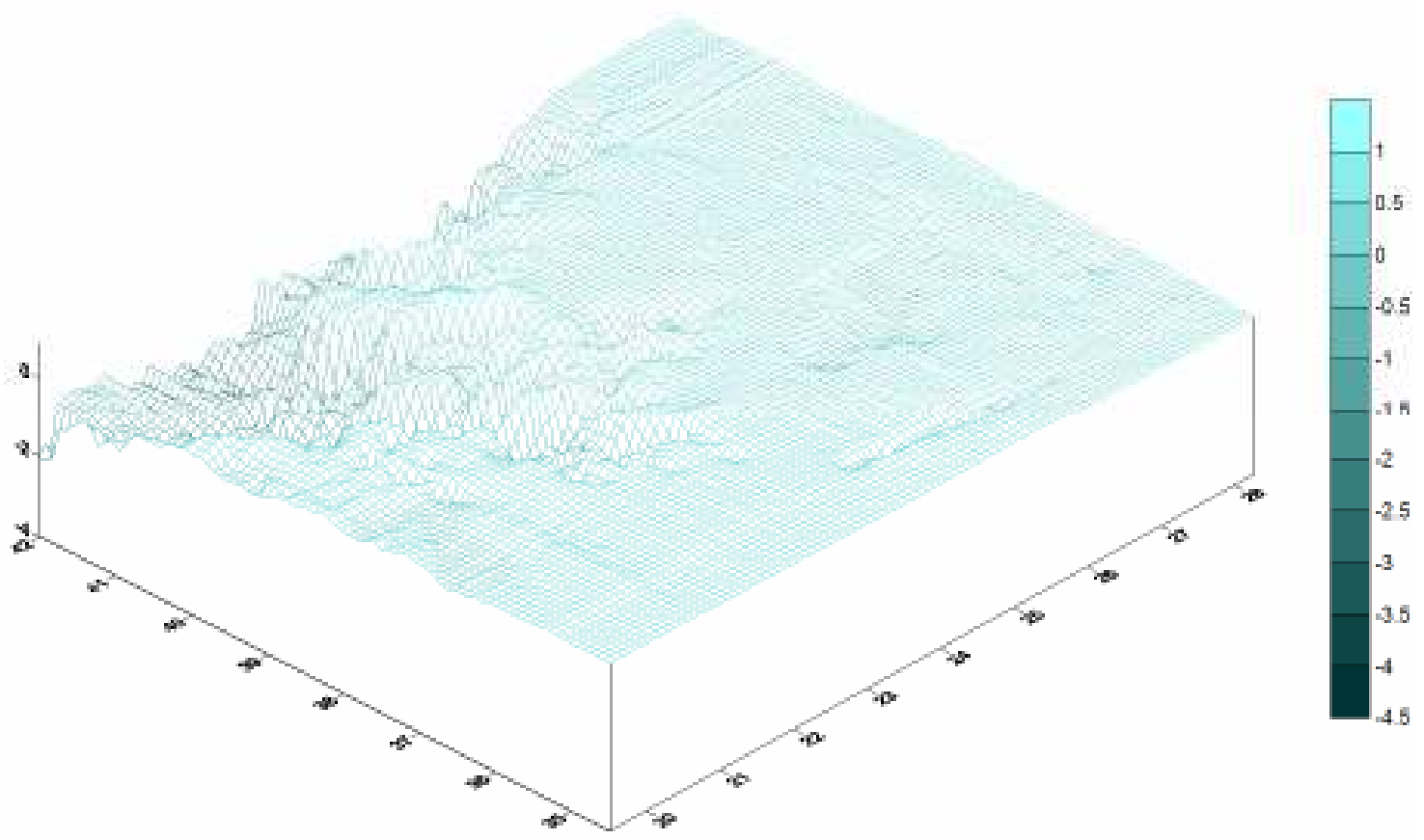

Fig. 4.6: Combined atmospheric correction for the new Greek gravimetric geoid model. Unit: $\mathrm{mm}$ 

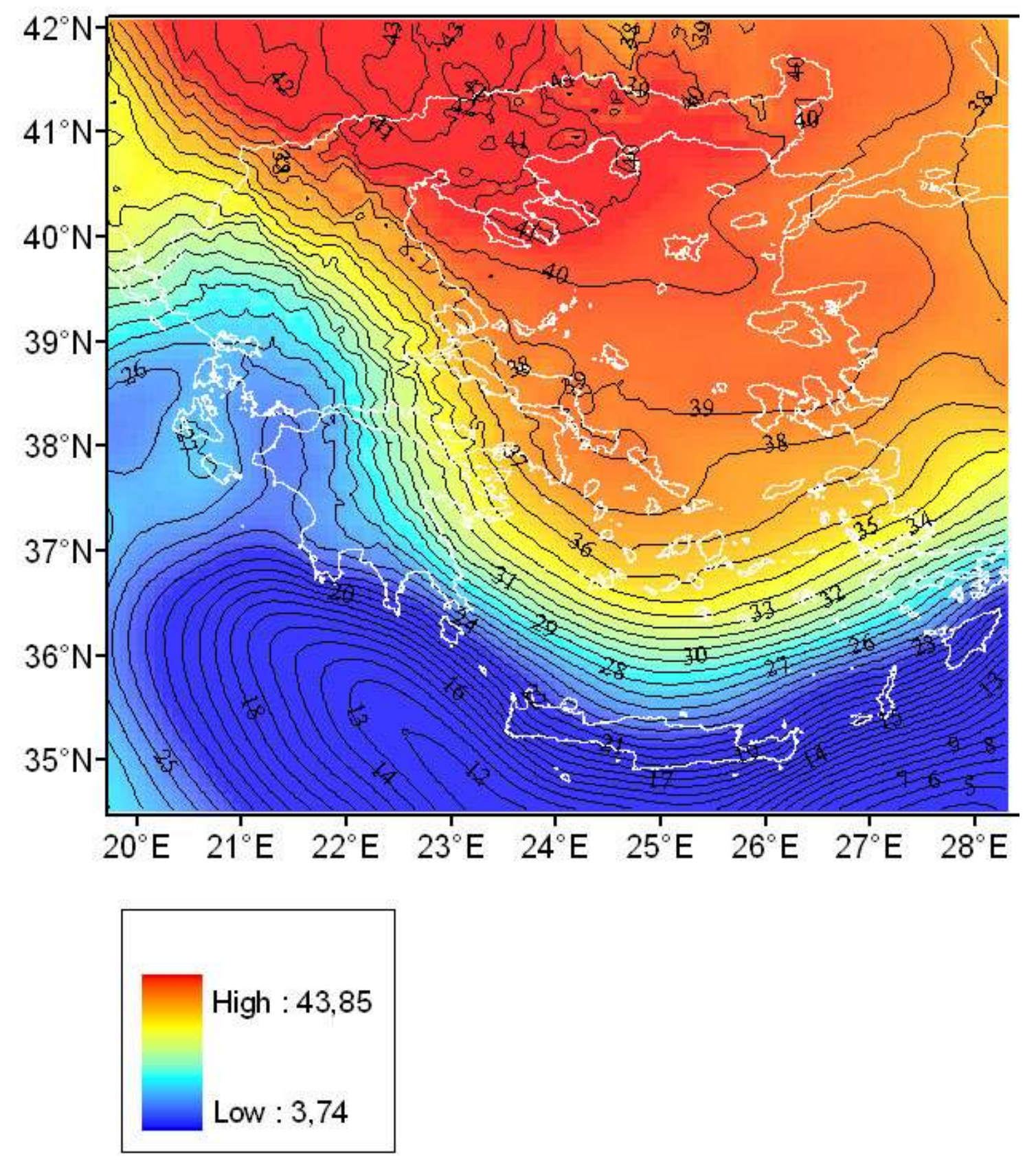

Fig. 4.7: The new Greek gravimetric geoid model in GRS80 


\section{Chapter 5}

\section{Evaluation of the Gravimetric Geoid Model}

Nowadays, the most reliable way to estimate the real potential of a gravimetric geoid, is to compare its result with the geoidal height derived separately from GPS/levelling data.

\subsection{Overview of current Greek geoid models}

The first attempt for determining a Greek geoid model, was conducted by D. Balodimos (Balodimos D.D, 1972) in 1972 who used values of the deflection of the vertical $\xi, \eta$ for determining an astrogeodetic geoid model. This solution was improved in 1978 by using supplementary $\xi, \eta$ values. In this solution, an astrogeodetic levelling was used with ED-50 as a reference system. In 1980 D.Arabelos (Arabelos 1980) computed a gravimetric geoid by Least Squares Collocation combining a spherical harmonics model with gravity anomalies. Discrepancies of the order of $77 \mathrm{~cm}$ resulted from the comparison with altimetric data from Geos-3.

Two combined geoid models were produced by I. Tziavos $(1984,1987)$, with the method of Least Squares Collocation (Katsabalos and Tziavos, 1991) in GRS80. For the first solution the GEM10B model, 783 mean free-air gravity anomalies $1^{0} \times 1^{0}$ for the region $24^{0} \leq \varphi \leq 52^{0}, 8^{0} \leq \lambda \leq 52^{0}, 4538$ mean free-air gravity anomalies of a $6^{\prime} \times 10^{\prime}$ grid for the region $33^{\circ} \leq \varphi \leq 43^{\circ}, 17^{0} \leq \lambda \leq 29^{\circ}$ and 200 points with $\xi, \eta$ values from Greece and neighboring countries were considered. The second solution uses the same data as the first one (except for the $1^{0} \times 1^{0}$ mean gravity anomalies) plus a GGM to degree and order 180 from Rapp (1981). The most significant difference between those two models is that the errors, in the second solution, are considered to be uncorrelated. Comparisons were carried out between the two solutions as well as with the geoid heights derived from SEASAT mission, with satisfactory results. The external accuracy of the second combined geoid model was estimated at $53 \mathrm{~cm}$. 
In 1988 (Arabelos and Tziavos, 1989) an improved solution of the two previous combined geoid models was presented, where 14356 mean gravity anomalies of a $6^{\prime} \times 10^{\prime}$ grid for the region $32^{0} \leq \varphi \leq 46^{\circ}, 12^{\circ} \leq \lambda \leq 30^{\circ}$ were used, along with 8000 point gravity anomalies, 120 points with $\xi, \eta$ values and mean height and ocean depth altimetric data of SEASAT and GEOSAT missions. The result was a combined geoid model in a grid of $6^{\prime} \times 10^{\prime}$.

In 1994 (Arabelos et al., 1994) a gravimetric geoid model of Eastern Mediterranean countries (including Greece), was presented using the model OSU 91A, point gravity anomalies for the region $30^{\circ} \leq \varphi \leq 45^{\circ}, 17^{0} \leq \lambda \leq 36^{\circ}$, a DTM of a $5^{\prime} \times 5^{\prime}$ grid for the region $29^{\circ} \leq \varphi \leq 43^{\circ}, 16^{\circ} \leq \lambda \leq 37^{\circ}$ and combined altimetric data of SEASAT, GEOSAT and ERS-1 missions.

In September 2002, an astrogeodetic geoid model was computed in NTUA (Tsinis 2002), using 103 points inside the Greek region and 93 points from the neighboring countries of Greece. A comparison was performed, between this astrogeodetic geoid, the smoothed geoid (Veis G., 1987) and the gravimetric geoid computed in this study. Fig. 5.1 and Fig. 5.2 depicts geoid heights along the parallel of $\varphi=38^{\circ}$ and along the meridian of $\lambda=26^{\circ}$ respectively. 


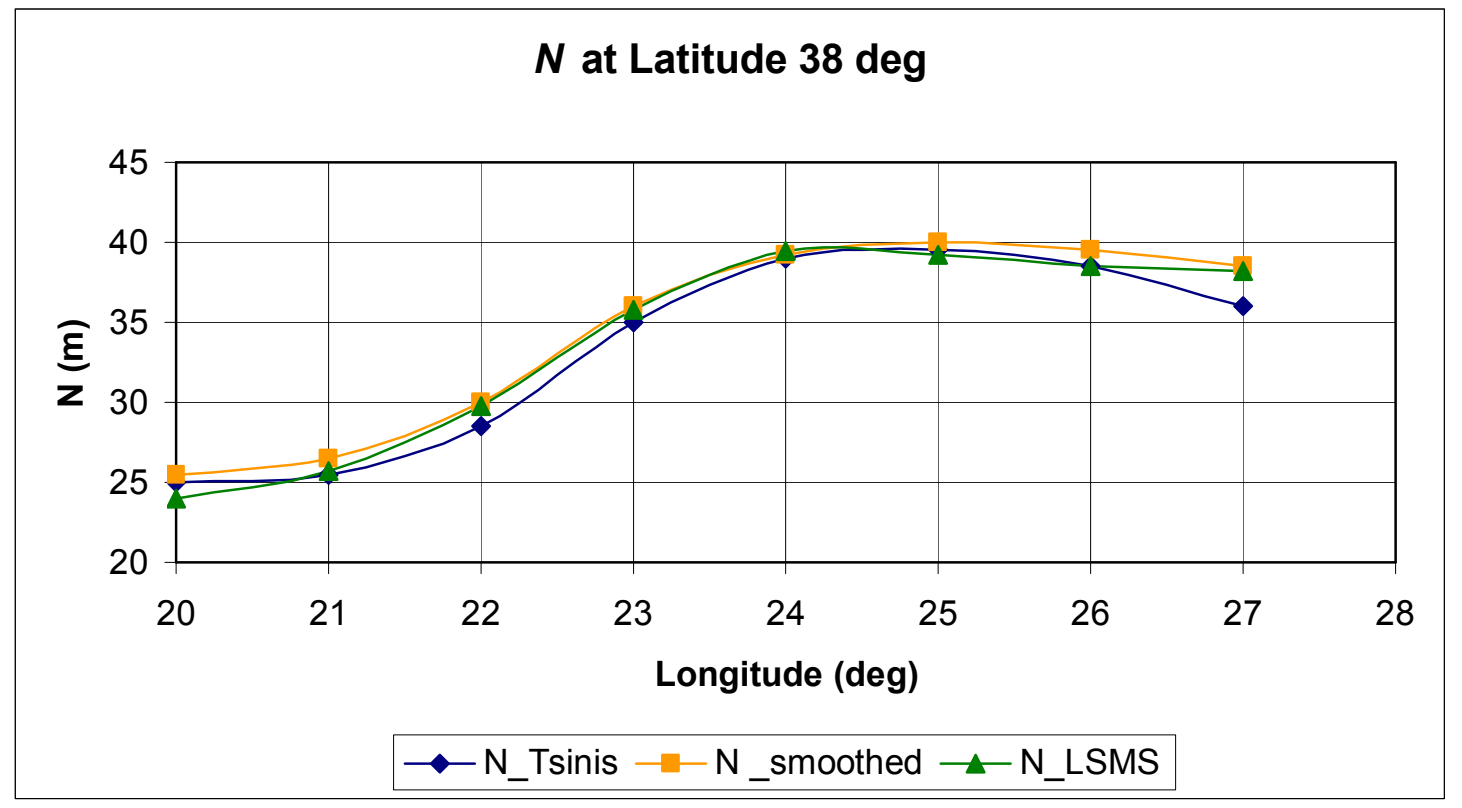

Fig. 5.1: $N$ values along the parallel of $\varphi=38^{\circ}$.

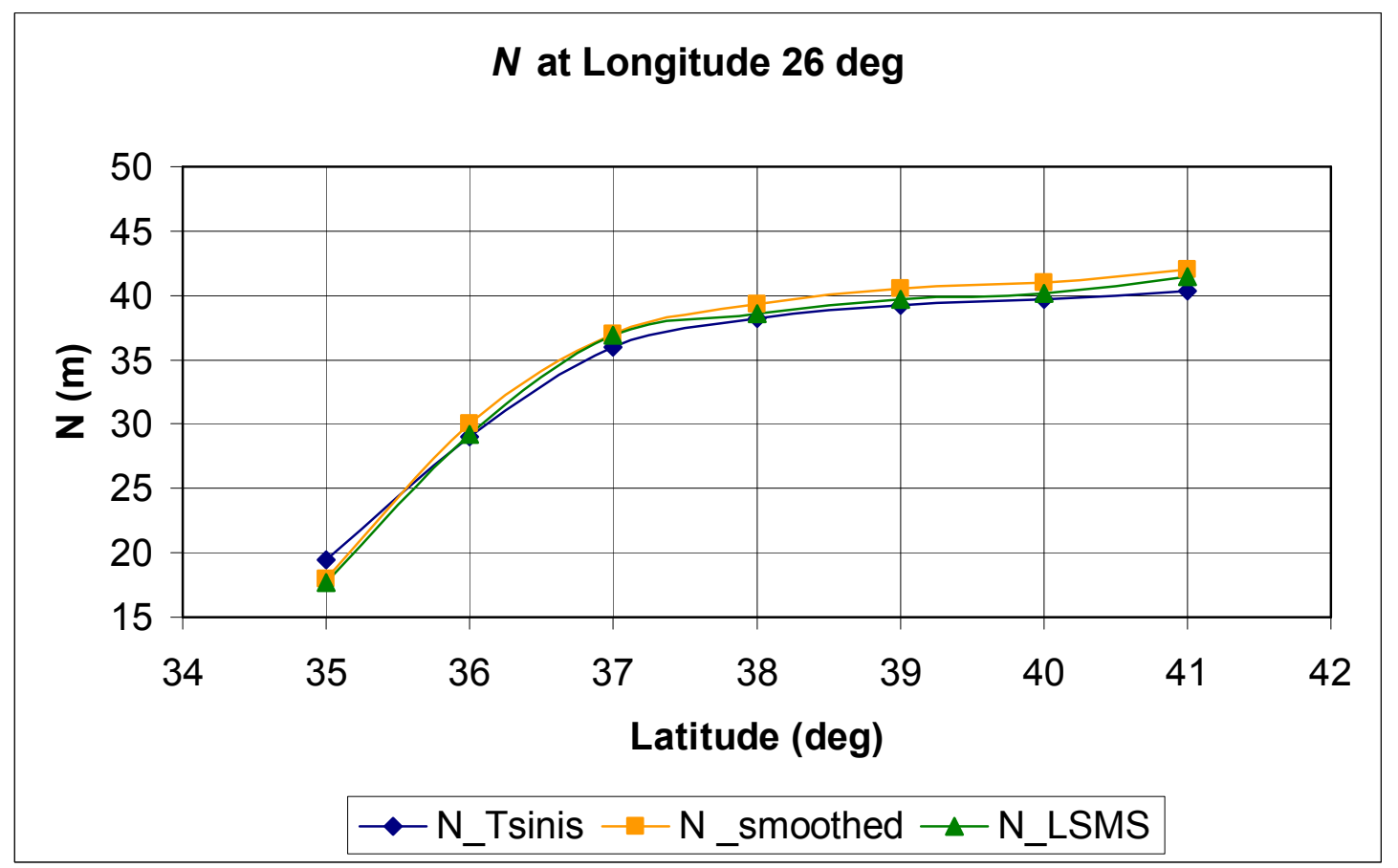

Fig. 5.2: $N$ values along the meridian of $\lambda=26^{\circ}$.

In 1982, the Hellenic Military Geographical Service computed a gravimetric geoid model for Greece from free-air gravity anomalies using Stokes' integration. Since then, 
there have been some additions and improvements to this model. In 2005, the old gravimetric geoid model was combined with the 201 first order GPS network stations, resulting in the new combined gravimetric geoid model, named FINGRAVGPSOLAC. After comparing the FINGRAV-GPSOLAC model with the 201 GPS data of the first-order network of Greece, an error of $\sigma \cong \pm 29 \mathrm{~cm}$ was estimated for the combined geoid model.

\subsection{Theoretical estimate of the accuracy of the gravimetric geoid}

\section{model}

The internal accuracy of the geoid heights estimations can be investigated in form of the global mean square error of the estimators. The expected Global Mean Square Error (GMSE) of the optimum least-squares model is derived as (Sjöberg 2003d):

$m_{\hat{N}}^{2}=f-c^{2} \sum_{k=2}^{L} \hat{s}_{k} h_{k}$

where $\hat{s}_{k}$ are the LS solutions to $s_{k}$ and $f$ is given by:

$f=c^{2}\left[\sum_{n=2}^{n_{\max }}\left(\frac{2}{n-1}-Q_{n}^{L}\right)^{2} \sigma_{n}^{2}+\sum_{n=2}^{M} Q_{n}^{2} \frac{c_{n} d c_{n}}{c_{n}+d c_{n}}+\sum_{n=2}^{n_{\max }} Q_{n}^{2} c_{n}\right]$

For this study, with $n_{\max }=2000$, maximum degree of modification and expansion $L=M=120$ (for GRACE02S) and truncation radius $\psi_{0}=3^{\circ}$, the global root mean square error is estimated to about $6 \mathrm{~cm}$. The expected MSE is only a theoretical estimate for the accuracy of the geoid, which is usually too optimistic and does not match exactly with practical results. The real potential of the gravimetric geoid is nowadays estimated when comparing its result with the externally derived geoid height from GPS/levelling measurements. 


\subsection{External Estimation of the accuracy of the gravimetric geoid}

\section{model}

The heights directly derived from GPS measurements are geodetic heights that refer to the ellipsoid defined by WGS84. The basic relationship between geodetic height $(h)$, geoid height $(N)$ and orthometric height $(H)$ is given by:

$h \approx H+N$

Fig. 5.3 depicts the principal of levelling with GPS and Table 5.1 shows the differences between the GPS/Levelling derived geoid height and the gravimetric geoid derived geoid height.

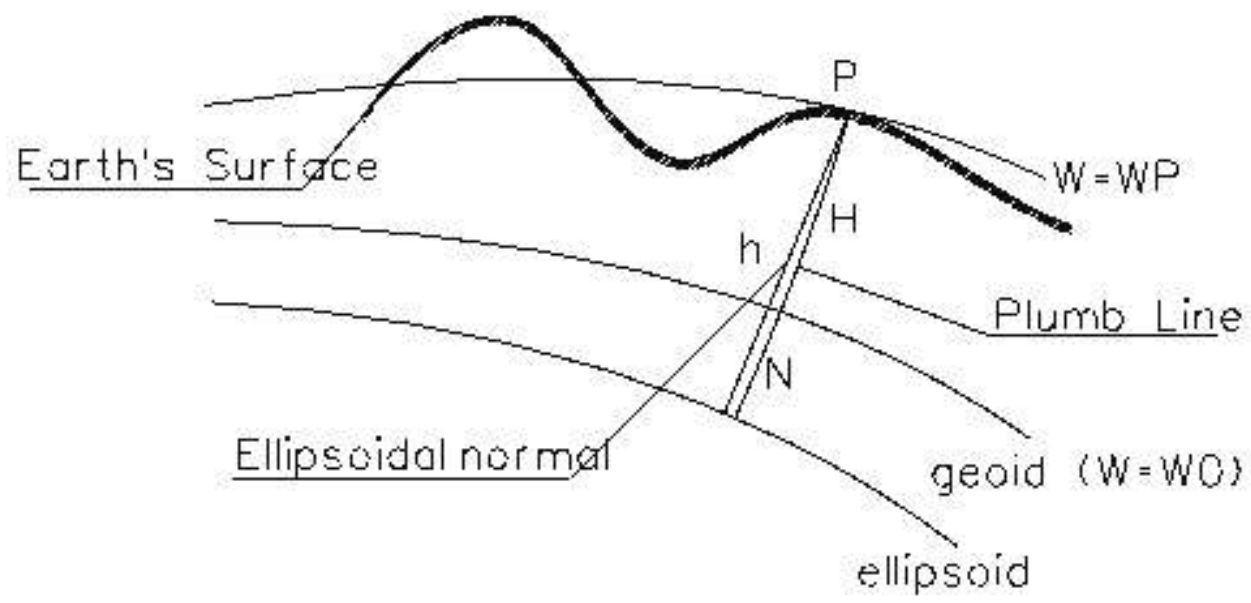

Fig. 5.3: Principal of levelling with GPS

Table 5.1: Geoid height values from GPS/Levelling and from the new gravimetric Geoid

\begin{tabular}{|c|c|c|c|c|}
\hline $\mathbf{N r}$ & Name & $\boldsymbol{N}_{\text {GPS / Levelling }}(\boldsymbol{m})$ & $\boldsymbol{N}_{\text {Geoid }}(\boldsymbol{m})$ & $\mathbf{D N}(\mathbf{m})$ \\
\hline 1 & STRN & 39.833 & 40.014 & -0.181 \\
\hline 2 & ELNK & 42.875 & 42.774 & 0.101 \\
\hline 3 & KOLI & 40.677 & 40.969 & -0.292 \\
\hline 4 & 335080 & 41.205 & 41.023 & 0.182 \\
\hline 5 & AS76 & 34.895 & 34.012 & 0.883 \\
\hline
\end{tabular}




\begin{tabular}{|c|c|c|c|c|}
\hline 6 & CS688 & 35.488 & 34.741 & 0.747 \\
\hline 7 & THOM & 25.782 & 25.632 & 0.15 \\
\hline 8 & VA64 & 36.743 & 36.350 & 0.393 \\
\hline 9 & KRPI & 38.392 & 38.129 & 0.263 \\
\hline 10 & MARA & 33.512 & 33.346 & 0.166 \\
\hline 11 & TR953 & 30.964 & 30.147 & 0.817 \\
\hline 12 & PTRF & 24.513 & 24.253 & 0.26 \\
\hline 13 & SKLO & 22.889 & 23.092 & -0.203 \\
\hline 14 & OXKF & 22.107 & 21.825 & 0.282 \\
\hline 15 & KRFL & 40.910 & 40.803 & 0.107 \\
\hline 16 & PLI & 27.034 & 26.365 & 0.669 \\
\hline 17 & ZAK2 & 17.522 & 17.538 & -0.016 \\
\hline 18 & SKDI & 20.550 & 19.706 & 0.844 \\
\hline st dev (m) & & & & $\mathbf{0 . 3 6 9}$ \\
\hline
\end{tabular}

\subsubsection{Agreement of absolute geoid heights}

In practice, because of the presence of different random and systematic errors in the values of $h, H$ and $N$ the simple model in Eq. (5.3.1) doesn't work properly. Those errors can be datum inconsistencies and long wavelength systematic errors in $N$, distortions in the orthometric height datum due to an over-constrained adjustment of the levelling network, effect of various geodynamic effects (e.g., specially tectonic deformation in Greece), improper or non-existent terrain/density modeling in the geoid modeling and orthometric heights and negligence of the sea surface topography (SST) at the tide gauges.

In order to reduce effect of the mentioned systematic errors (for example the difference in the value of GM constant between the GRS80 and the EIGEN-GRACE02S model used for the computations) in evaluation of geoid models, several systematic parameter models can be used in order to fit the quasi-geoid to a set of GPS levelling points through an integrated least squares adjustment. Such a comparison is traditionally based on the following model (Kotsakis and Sideris 1999): 
$\Delta N=N_{i}^{G P S}-N_{i}=h_{i}-H_{i}-N_{i}=\alpha_{t}^{T} x+\varepsilon_{i}$

where $N_{i}$ is the interpolated geoidal height value for the $i$ GPS point, considering points from the geoid model that exist in the neighborhood., $x$ is a $n \times 1$ vector of unknown parameters (where $n$ the number of the GPS/levelling points), $a_{i}$ is a $n \times 1$ vector of known coefficients, and $\varepsilon_{i}$ denotes a residual random noise term. The parametric model $\alpha_{t}^{T} x$ is supposed to describe the mentioned systematic errors and inconsistencies inherent in the different height data sets. For the scope of this study, the 7-parameter model was chosen:

$$
a_{i}=\left(\begin{array}{c}
\cos \phi_{i} \cos \lambda_{i} \\
\cos \phi_{i} \sin \lambda_{i} \\
\sin \phi_{i} \\
\cos \phi_{i} \sin \phi_{i} \cos \lambda_{i} / W_{i} \\
\cos \phi_{i} \sin \phi_{i} \sin \lambda_{i} / W_{i} \\
\sin ^{2} \phi_{i} / W_{i} \\
1
\end{array}\right) \quad \text { and } \quad x=\left(\begin{array}{c}
x_{1} \\
x_{2} \\
x_{3} \\
x_{4} \\
x_{5} \\
x_{6} \\
x_{7}
\end{array}\right)
$$

where $\phi, \lambda$ the horizontal geodetic coordinates of the GPS/levelling points and,

$$
W_{i}=\left(1-e^{2} \sin ^{2} \phi_{i}\right)^{1 / 2},
$$

where $e$ is the first eccentricity of the reference ellipsoid. We then obtain the following matrix system of observation equations:

$$
A x=\Delta N-\varepsilon,
$$


where $A$ is the design matrix composed of one row $a_{i}^{T}$ for each observation $\Delta N_{i}$. The least squares adjustment to this equation utilizing the mean squares of the residuals $\varepsilon_{i}$, becomes:

$\hat{x}=\left(A^{T} A\right)^{-1} A^{T} \Delta N$

yielding the residuals

$\hat{\varepsilon}=\Delta N-A \hat{x}=\left[I-A\left(A^{T} A\right)^{-1} A^{T}\right] \Delta N$

The standard deviation of the adjusted values for the residuals $\hat{\varepsilon}$ is traditionally taken as the external measure of the absolute accuracy of the geoid model. The final residual values though, are not the exact errors of the gravimetric or GGM geoid models, because they include also some part of errors from GPS/levelling observations. The $N_{i}$ values at the GPS/levelling position that are given from the geoid model, have an uncertainty which depends on the density of the terrestrial gravity data in the region that the spherical cap is capturing. Thus, the values of the residuals $\hat{\varepsilon}$ also depend on the density of the gravity data around the computation point each time.

Fig. 5.4 shows the distribution of the GPS/levelling points inside the Greek region and the absolute value of the residuals $\varepsilon_{i}$ with the geoid model after the 7-parameter fitting. 

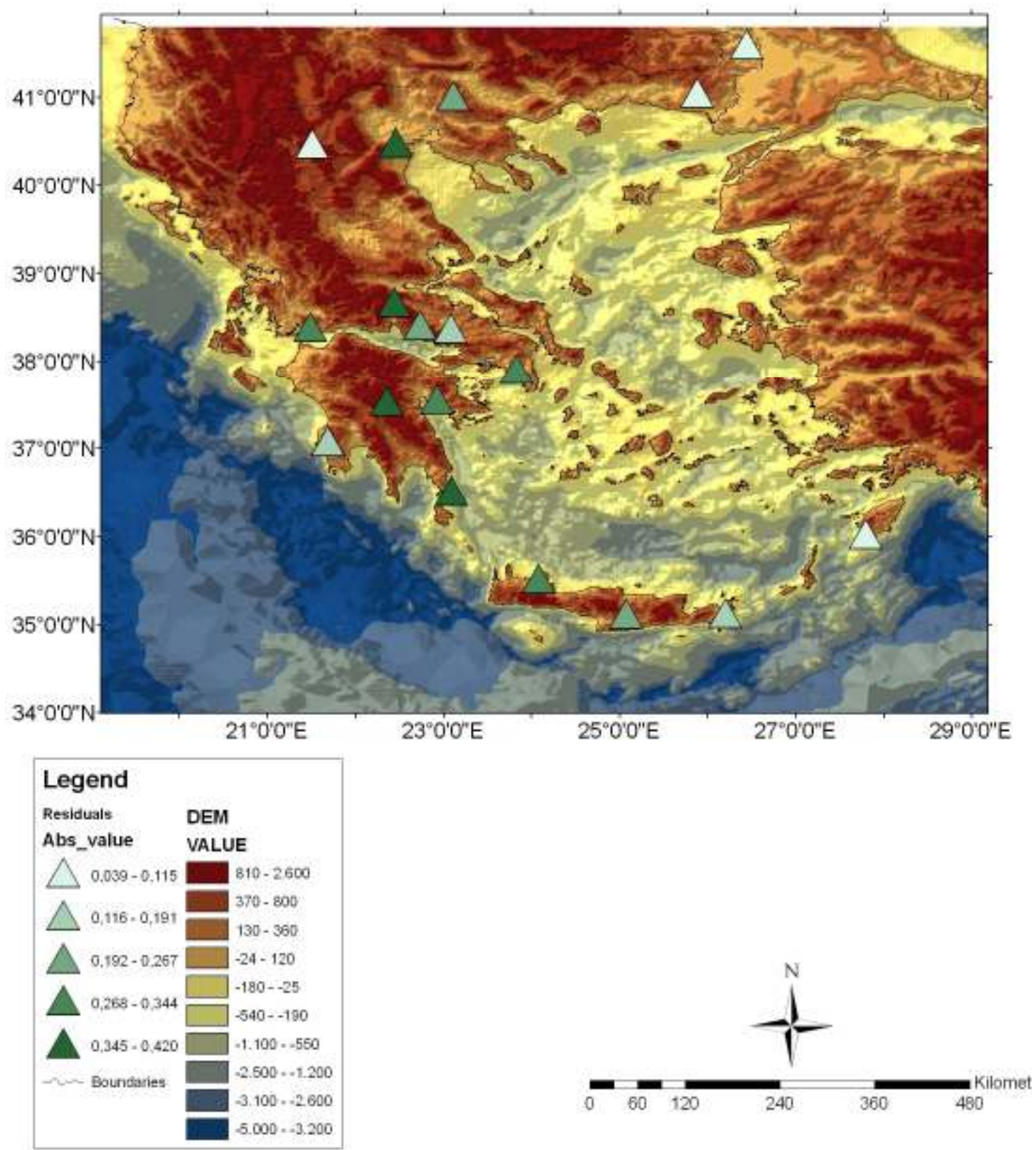

Fig. 5.4: Distribution of the GPS/levelling points inside the Greek region. The absolute value of the residuals $\varepsilon_{i}$ with the geoid model after the 7-parameter fitting is visualized with the difference in the color scale.

Table 5.2 shows the result from evaluating the geoid model, using the approximate geoid height $\tilde{N}$. There are differences shown before and after the 7-parameter fitting as long as results from different GGM models. 
Table 5.2: Geoid height differences between the GPS and the approximate Geoid values, before and after the 7-parameter fitting. Results are displayed for all the GGM models used.

\begin{tabular}{|c|c|c|c|c|c|c|}
\hline & \multicolumn{2}{|c|}{ EIGEN-GRACE02S } & \multicolumn{2}{|c|}{ EIGEN-GL04C } & \multicolumn{2}{c|}{ EGM96 } \\
\hline Name & Before & After & Before & After & Before & After \\
& Fitting & fitting & Fitting & fitting & Fitting & fitting \\
\hline & DNappr. (m) & $\boldsymbol{\varepsilon}(\mathbf{m})$ & DNappr. (m) & $\boldsymbol{\varepsilon}(\mathbf{m})$ & DNappr. (m) & $\boldsymbol{\varepsilon}(\mathbf{m})$ \\
\hline STRN & -1.120 & -0.012 & -1.164 & -0.059 & -0.697 & 0.011 \\
ELNK & -0.942 & 0.215 & -0.868 & 0.271 & -0.560 & 0.245 \\
KOLI & -1.247 & -0.273 & -1.193 & -0.217 & -0.955 & -0.262 \\
335080 & -1.044 & -0.016 & -1.081 & -0.075 & -0.737 & -0.039 \\
AS76 & -0.073 & 0.445 & -0.134 & 0.442 & -0.082 & 0.510 \\
CS688 & -0.247 & 0.228 & -0.328 & 0.211 & -0.342 & 0.264 \\
THOM & -0.791 & -0.243 & -0.867 & -0.286 & -0.901 & -0.243 \\
VA64 & -0.547 & -0.100 & -0.593 & -0.074 & -0.713 & -0.127 \\
KRPI & -0.684 & -0.309 & -0.747 & -0.292 & -0.931 & -0.335 \\
MARA & -0.785 & -0.320 & -0.932 & -0.415 & -1.106 & -0.337 \\
TR953 & -0.225 & 0.280 & -0.315 & 0.228 & -0.585 & 0.233 \\
PTRF & -0.695 & -0.099 & -0.596 & 0.004 & -1.142 & -0.135 \\
SKLO & -1.144 & -0.262 & -1.062 & -0.238 & -1.721 & -0.151 \\
OXKF & -0.729 & 0.237 & -0.678 & 0.206 & -1.416 & 0.239 \\
KRFL & -0.914 & -0.020 & -0.925 & 0.003 & -0.650 & -0.075 \\
PLI & -0.301 & 0.323 & -0.268 & 0.360 & -0.815 & 0.331 \\
ZAK2 & -0.983 & -0.160 & -0.947 & -0.188 & -1.661 & -0.269 \\
SKDI & -0.124 & 0.086 & -0.134 & 0.120 & -0.297 & 0.141 \\
\hline dev(m) & $\mathbf{0 . 3 7 0}$ & $\mathbf{0 . 2 4 1}$ & $\mathbf{0 . 3 5 1}$ & $\mathbf{0 . 2 4 8}$ & $\mathbf{0 . 4 4 1}$ & $\mathbf{0 . 2 5 7}$ \\
\hline
\end{tabular}

As one may notice in Table 5.2, there is a significant improvement in the standard deviation of the geoid height differences before and after the 7-parameter fitting, in all the GGM models tested. The standard deviation after the fitting for EIGENGRACE02S and EIGEN-GL04C model is almost identical, while the standard 
deviation for EGM96 model is a bit bigger than the other models. Table 5.2 shows the result from evaluating the geoid model using the corrected/precise geoid height $\hat{N}$ for the EIGEN-GRACE02S model which was chosen for the final computations.

Table 5.3: Geoid height differences between the GPS and the final geoid values, before and after the 7-parameter fitting. Results are displayed only for the EIGEN-GRACE02S model which was chosen for the computations.

\begin{tabular}{|c|c|c|c|}
\hline & & EIGEN - GRACEO2S & \\
\hline \multirow[t]{2}{*}{$\mathbf{N r}$} & Name & Before Fitting & After fitting \\
\hline & & DN (m) & $\varepsilon(\mathrm{m})$ \\
\hline 1 & STRN & -0.181 & -0.044 \\
\hline 2 & ELNK & 0.106 & 0.200 \\
\hline 3 & KOLI & -0.292 & -0.380 \\
\hline 4 & 335080 & 0.185 & 0.104 \\
\hline 5 & AS76 & 0.886 & 0.420 \\
\hline 6 & CS688 & 0.744 & 0.251 \\
\hline 7 & THOM & 0.148 & -0.315 \\
\hline 8 & VA64 & 0.394 & -0.116 \\
\hline 9 & KRPI & 0.261 & -0.297 \\
\hline 10 & MARA & 0.161 & -0.325 \\
\hline 11 & TR953 & 0.816 & 0.357 \\
\hline 12 & PTRF & 0.260 & -0.122 \\
\hline 13 & SKLO & -0.203 & -0.283 \\
\hline 14 & OXKF & 0.282 & 0.266 \\
\hline 15 & KRFL & 0.106 & 0.039 \\
\hline 16 & PLI & 0.670 & 0.345 \\
\hline 17 & ZAK2 & -0.013 & -0.185 \\
\hline 18 & SKDI & 0.848 & 0.085 \\
\hline & st $\operatorname{dev}(\mathrm{m})$ & 0.369 & 0.266 \\
\hline
\end{tabular}

As shown in Table 5.3, the standard deviation of the corrected geoid height differences for the EIGEN-GRACE02S model before the fitting is almost the same as the standard 
deviation of the approximate geoid height. The standard deviation after the fitting though, has a bit larger value than the corresponding standard deviation of the approximate geoid height.

The external accuracy of the previous Greek geoid models was available only for two of them. The external accuracy for the first one (Tziavos, 1984) was estimated at $53 \mathrm{~cm}$, while for the second one (FINGRAV-GPSOLAC - Hellenic Military Geographical Service, Mylona, 2005) at $29 \mathrm{~cm}$. From evaluating the new gravimetric geoid model with the GPS/levelling data, it seems that the external accuracy of the new model computed in this study, is better $( \pm 27 \mathrm{~cm})$ than those two previous models.

In a case study, considering the accuracies of the ellipsoidal and orthometric heights as $\sigma_{h} \approx \pm 10 \mathrm{~cm}$ and $\sigma_{H} \approx \pm 20 \mathrm{~cm}$ respectively and their errors to be uncorrelated, then from error propagation we have:

$\sigma_{N^{G P S / L e v}}^{2}=\sigma_{h}^{2}+\sigma_{H}^{2}$

and

$\sigma_{\Delta N}^{2}=\sigma_{N}^{2}+\sigma_{N^{G P S / L e v}}^{2}, \quad \sigma_{N}^{2}=\sigma_{\Delta N}^{2}-\sigma_{N^{G P S / L e v}}^{2}$

From previous computations, the standard deviation of the geoid height differences after the fitting was estimated at $\sigma_{\Delta N}= \pm 0.27 \mathrm{~m}$. Hence, from Eq. (5.3.1.8) and (5.3.1.7) we have $\sigma_{N}= \pm 0.14 m$ which can be considered as an estimate of the absolute accuracy of the gravimetric geoid model. 


\subsubsection{Agreement of the relative geoid heights}

Because of the presence of different systematic errors and adjustment of the GPS/levelling and gravity data, the estimation of the agreement of the absolute geoid heights stemming from the GPS/Levelling data and the gravimetric geoid model, usually can not show the real potential of the geoid model. It is well known, that GPS and levelling observations have very good accuracies in the relative sense, because most of the systematic errors are cancelled or eliminated through the differencing of the observations.

Hence, the new Greek gravimetric geoid model was also evaluated in a relative sense by using the GPS/levelling data. For this purpose, Eq (5.3.1) was used as follows:

$\Delta H_{\text {GPS-Geoid }}=\Delta h_{G P S}-\Delta N_{\text {Geoid }}$

where in $\Delta N_{\text {Geoid }}$ the gravimetric geoid values after the 7-parameter fitting is used, meaning that $\Delta N_{\text {Geoid }}=\left(N_{2}-N_{1}\right)+\left(\varepsilon_{2}-\varepsilon_{1}\right)$

Then the differences between two different orthometric height differences, i.e. from levelling $\left(\Delta H_{\text {Level }}\right)$ and from GPS minus Geoid $\left(\Delta H_{G P S-G e o i d}\right)$, were derived:

$$
\delta \Delta H_{\text {Geoid-Level }}=\Delta H_{\text {GPS-Geoid }}-\Delta H_{\text {Level }}
$$

The relative differences between the GPS/geoid heights and the levelling heights becomes in part per million ( $\mathrm{ppm})$ :

$$
p p m=\text { mean }\left|\frac{\left(\delta \Delta H_{\text {Geo-Level }}\right)_{m m}}{D_{i j(\mathrm{~km})}}\right|
$$

where $D_{i j}$ is the length of the baseline. The average distance between the GPS/levelling points is $197 \mathrm{~km}$. Table 5.4 shows the results from the agreement between the relative values of the gravimetric and GPS/Levelling derived geoid height. The new gravimetric model fits the GPS/levelling data with $0.9 \mathrm{ppm}$. 
Table 5.4: Estimation of the agreement between the relative values of the gravimetric and GPS/Levelling derived geoid height

\begin{tabular}{|c|c|c|c|c|c|}
\hline Dh (m) & DN (m) & $\begin{array}{c}\text { DH_GPS- } \\
\text { GEOID (m) }\end{array}$ & $\begin{array}{c}\text { DH_Levelling } \\
(\mathbf{m})\end{array}$ & $\begin{array}{c}\text { Distance } \\
\text { Dij (m) }\end{array}$ & $\left(\frac{\left(\delta \Delta H_{\text {Geo-Level }}\right)_{m m}}{\boldsymbol{D}_{\boldsymbol{i j}(\mathbf{k m})}}\right.$ \\
\hline 850.166 & 3.003 & 847.407 & 847.124 & $287,042.585$ & 0.135 \\
-597.712 & -2.384 & -595.908 & -595.514 & $81,251.003$ & 2.286 \\
$1,209.421$ & 0.538 & $1,209.367$ & $1,208.892$ & $80,220.192$ & 0.117 \\
$-1,171.529$ & -6.695 & $-1,164.519$ & $-1,165.219$ & $215,127.454$ & 1.787 \\
259.118 & 0.561 & 258.389 & 258.525 & $38,840.511$ & 0.821 \\
-571.346 & -9.676 & -562.237 & -561.640 & $109,004.436$ & 0.274 \\
49.124 & 10.917 & 38.406 & 38.162 & $139,825.039$ & 0.320 \\
91.656 & 1.598 & 89.878 & 90.008 & $84,001.876$ & 0.594 \\
7.787 & -4.811 & 12.570 & 12.667 & $88,975.271$ & 0.778 \\
683.317 & -2.517 & 686.516 & 685.865 & $50,383.600$ & 0.623 \\
-554.161 & -6.374 & -548.266 & -547.710 & $77,493.039$ & 0.990 \\
-205.834 & -1.322 & -204.673 & -204.210 & $276,085.569$ & 1.095 \\
605.948 & -0.718 & 607.215 & 606.730 & $101,034.757$ & 0.631 \\
59.621 & 18.751 & 40.644 & 40.819 & $661,483.310$ & 0.078 \\
-315.303 & -14.131 & -300.866 & -301.428 & $559,141.638$ & 0.457 \\
-9.920 & -9.358 & -1.093 & -0.408 & $320,873.614$ & 0.480 \\
18.569 & 2.438 & 16.401 & 15.541 & $175,483.197$ & 3.361 \\
\hline & & & & $\mathbf{p p m}$ & $\mathbf{0 . 8 7 2}$ \\
\hline
\end{tabular}




\section{Chapter 6}

\section{Conclusions and Recommendations}

The computation of a regional gravimetric geoid model with proper accuracy is a difficult task which needs special notice and full investigation in all the phases of computations, in order to produce good results. In this research, the least squares modification of Stokes' method by the KTH approach was used for combining different heterogeneous data in an optimum way.

The workflow of this study can be summarized as follows:

$>$ Gathering of the necessary database for the computations (i.e. the gravity database, the DEM and the GPS/Levelling data).

$>$ Evaluation of the gravity database and formatting of the gravity anomaly grid for the area.

$>$ Investigation for the best choice of the GGM to be used for the computations and for several parameters necessary for the computations.

$>$ Computation of the approximate geoid height using the stochastic approach of Stokes's formula modification.

$>$ Computation of the additive correction in the KTH scheme. Computation of the precise/corrected geoid height by adding them to the approximate geoid height.

$>$ Evaluation of the gravimetric geoid model with GPS/Levelling data.

The conclusions of this study are the following:

$>$ The cross validation technique was used for detections of outliers in the gravity dataset, and 87 gravity measurements were omitted from the dataset with an interpolation error $\varepsilon>35 \mathrm{mGals}$.

$>$ The investigation for choosing the best fitting GGM for the study area resulted in choosing the EIGEN-GRACE02S (satellite only) model for the geoid computations. The EIGEN-GRACE02S model was estimated to minimize better 
the truncation bias and yielded the best results after fitting with the GPS/levelling data.

$>$ The theoretical estimate of the accuracy of the new gravimetric model was estimated at $6 \mathrm{~cm}$.

$>18 \mathrm{GPS} /$ Levelling points were chosen for evaluating the geoid model

$>$ The agreement between the absolute geoid heights stemming from the GPS/Levelling data and the gravimetric geoid model, after a 7-parameter fitting, was estimated at $24 \mathrm{~cm}$ for the approximate geoid height and at $27 \mathrm{~cm}$ for the corrected/precise geoid height.

$>$ The agreement between the relative geoid heights stemming from the GPS/Levelling data and the gravimetric geoid model, after a 7-parameter fitting, was estimated at $0.9 \mathrm{ppm}$.

$>$ In a case study considering the accuracies of the ellipsoidal and orthometric heights as $\sigma_{h} \approx \pm 10 \mathrm{~cm}$ and $\sigma_{H} \approx \pm 20 \mathrm{~cm}$ respectively, the absolute accuracy of the gravimetric geoid model was estimated at $\sigma_{N}= \pm 14 \mathrm{~cm}$.

$>$ The new Greek gravimetric geoid model seems to have a better external accuracy $( \pm 27 \mathrm{~cm})$ than the FINGRAV-GPSOLAC model (Hellenic Military Geographical Service, 2005) estimated at $\pm 29 \mathrm{~cm}$ and the geoid by (Tziavos, 1984) estimated at $\pm 53 \mathrm{~cm}$.

Our main recommendations for further work are the following:

$>$ One of the biggest constraints in this study was the lack of gravity measurements in the sea region and in the neighbouring countries of Greece. For the computations, it was essential that the extended region, formatted by an offset of $3^{\circ}$ from our target area (the same as the truncation cap size $\psi_{0}^{o}=3^{\circ}$ ), contained terrestrial gravity measurements. Since there were no gravity measurements available in those regions, the empty blocks were given gravity anomaly values from EGM96. It is evident that in order to achieve better results, terrestrial gravity measurements from the neighbouring countries must be taken into account. Altimetric data in the sea region where there is no gravity information can also be combined in an optimum way into the solution. Finally, better GGM 
models up to much higher degree and order, which are in the finalisation process, can yield much better gravity anomaly values for the empty blocks.

$>$ The DWC correction is an essential correction for obtaining the corrected geoid height as shown in Eq. (2.4.1) and it may reach several cm. A more extended DEM model is therefore needed for computing the DWC correction and thus determining a more precise geoid model. A suggestion could be to combine the existing DEM model with values from a global DEM model.

$>$ The DEM and the GPS/levelling points should be evaluated before using them in geoid computations and geoid evaluation respectively. The existing DEM includes errors stemming from interpolating the height values from existing contour maps, among others. There are numerous elevation datasets with global or near-global coverage (GTOPO30, NOAA, STRM, ETOPO, Sandwell-Smith DEM) that can be used instead of the Greek DEM. A detailed investigation for which DEM model is more accurate for the Greek region is recommended as further work. A research should also be conducted for the quality of the GPS/levelling data used for evaluating the geoid model. Observation time period, accuracy estimation of the orthometric heights, must be clarified, geodynamic effects must be taken into account and datum/epochs of the GPS points must be aligned.

The main difference between the KTH approach and other methods in geoid determination is that the KTH approach employs unreduced data. This results in larger discretisation errors than in the methods using reduced data, as the free-air anomaly is known to be more sensitive to the topography. If there is rough topography in the region, the interpolation cannot always be successful, thus resulting in discretisation errors. The discretisation error occurs due to the loss of short wavelength gravity information when estimating the mean gravity anomalies $\Delta g$ from point gravity data. The following technique is proposed to reduce the discretisation error (Kiamehr 2005a). First a topographic correction (e.g., using the RTM method / Forsberg-1984) is made, that results into reduced gravity anomalies, which are assumed to be smoother than the original ones. Then the observations are interpolated into a denser grid and finally the topographic corrections are reserved, i.e. the masses are restored. An accurate DEM is required for this purpose, which should be available with at least the 
same resolution as the new interpolated grid. Kiamehr (2006d) concluded that after employing this technique for the Iranian geoid model, a significant improvement in the order of $0.34 \mathrm{~m}$ in the approximate geoid height was achieved. Even though Greece is not as mountainous as Iran, it also has a rough topography with mountains up to $2918 \mathrm{~m}$. Thus, the above data treatment for eliminating the discretisation errors is essential for a more precise gravimetric geoid model. 


\section{References}

Arabelos, D., (1980): Untersuchungen zur gravimetrischen Geoidbestimmung dargestellt am Testgebiet Griechenland, Wiss. Arb. Univ. Hann., Nr. 98, Dissertation

Arabelos D., (1989): Gravity field approximation in the area of Greece with emphasis on the local characteristics. Boll. Geod. 63, 69-84

Arabelos D, Tziavos I.N. (1994): Analysis of IERS-1 and TOPEX altimeter data in the Mediterranean Sea. Presented at the XIX General Assembly of EGS, Grenoble 1994

Balodimos D.D., (1972): Geoidal Studies in Greece, PhD Dissertation, Oxford

Ellmann A. (2001): Least squares modification of Stokes' formula with applications to the Estonian geoid. Royal Institute of Technology, Division of Geodesy Report No. 1056 (Licentiate Thesis), Stockholm

Ellman A. and Sjöberg LE (2004): Ellipsoidal correction for the modified Stokes formula. Boll. Geod. Sci. Aff., 63(No.3).

Ellmann A. (2005a): Computation of three stochastic modifications of Stokes's formula for regional geoid determination. Computers and Geosciences, 31/6, pp.742-755.

Ellmann A. (2005b): Two deterministic and three stochastic modifications of Stokes's formula: a case study for the Baltic countries. Journal of Geodesy, 79, 11-23.

Fan H. (1998): On an Earth ellipsoid best-fitted to the Earth surface. Journal of Geodesy, 72(3):154-160.

Forsberg R (1984): A study of Terrain Reductions, Density Anomalies and Geophysical Inversion Methods in Gravity Field Modelling, Rep 255, Dept Geod Sci, Ohio State Univ, Columbus. 
Förste, C., Schmidt, R., Stubenvoll, R., Flechtner, F., Meyer, U., König, R., Neumayer, H., Biancale, R., Lemoine, J.-M., Bruinsma, S., Loyer, S., Barthelmes, F., and Esselborn, S., 2007. The GeoForschungsZentrum Potsdam/Groupe de Recherche de Geodesie Spatiale satellite-only and combined gravity field models: EIGEN-GL04S1 and EIGEN-GL04C. Journal of Geodesy, doi:10.1007/s00190-007-0183-8.

Geisser S., and Eddy W.F., (1979): A predictive approach to model selection. Journal of the American Statistical Association, 74(365), 153-160.

Heiskanen WA, Moritz H (1967): Physical Geodesy. W H Freeman and Co., New York, London and San Francisco.

GETECH (2007): Gravity point data for Greece, Geophysical Exploration Technology (GETECH), University of Leeds.

Hellenic Military Geographical Service, Mylona (2005): The geoid model of Greece in WGS84, combined by GPS and gravity measurements. Vol. 152, Publication 20032005.

Kiamehr R (2005a): Qualification and refinement of the gravity database based on cross-validation approach, A case study of Iran, Proc Geomatics 2004 (84) Conferences, National Cartographic Centre of Iran, Teheran, Iran, Revised version, submitted J. Acta Geodaetica et Geophysica.

Kiamehr R and Sjöberg LE (2005b): Effect of the STRM global DEM on the determination of a high-resolution geoid model: A case study in Iran, Journal of Geodesy, 79(9):540-551

Kiamehr R (2006a): A strategy for determining the regional geoid in developing countries by combining limited ground data with satellite-based global geopotential and topographical models: A case study of Iran, Journal of Geodesy, 79(10,11):602612. 
Kiamehr R (2006b): Hybrid precise gravimetric geoid model for Iran based on recent GRACE and STRM data and the least squares modification of Stokes' formula, $J$. Physics of Earth and Space, 32(1):7-23.

Kiamehr R (2006c): The impact of lateral density variation model in the determination of precise gravimetric geoid in mountainous areas: A case study of Iran, in press Geophysical Journal International.

Kiamehr, Ramin (2006d): Precise Gravimetric Geoid Model for Iran Based on GRACE and SRTM Data and the Least-Squares Modification of Stokes' Formula: with Some Geodynamic Interpretations, (Ph.D. Thesis), Royal Institute of Technology, http://urn.kb.se/resolve?urn=urn:nbn:se:kth:diva-4125, Stockholm, Sweden.

Kotsakis C, Sideris MG (1999): On the adjustment of combined GPS/levelling/geoid networks. Journal of Geodesy, Vol 73(8),412-421.

Moritz H. (1980): Advanced physical geodesy, Herbert Wichmann Verlag Karlsruhe, 1980.

Press WH, Teukolsky SA, Vetterling WT, Flannery BP (1992): Numerical recipes in FORTRAN $2^{\text {nd }}$ edition. Cambridge University Press, Cambridge

Rapp RH and Pavlis NK (1990): The development and analysis of geopotential coefficients models to spherical harmonic degree 360, J. Geophys. Res., 95(B13)21885-21911

Reigber Christoph, Schmidt Roland, Flechtner Frank, König Rolf, Meyer Ulrich, Neumayer Karl-Hans, Schwintzer Peter, Sheng Yuan Zhu (2005): An Earth gravity field model complete to degree and order 150 from GRACE: EIGEN-GRACE02S, Journal of Geodynamics 39(1),1-10

Sjöberg LE (1998): The atmospheric geoid and gravity corrections. Boll Geod Sci Aff, 57(4):421-435 
Sjöberg LE (1999a): On the downward continuation error at the Earth's surface and the geoid of satellite derived geopotential models. Boll Geod Sci Affini 58(3):215-229

Sjöberg LE (1999b): The IAG approach to the atmospheric geoid correction in Stokes formula and a new strategy. Journal of Geodesy, 73(7):362-366

Sjöberg LE (2000): On the topographic effects by the Stokes-Helmert method of geoid and quasi-geoid determinations. Journal of Geodesy, 74(2):255-268

Sjöberg LE (2001a): Topographic and atmospheric corrections of gravimetric geoid determination with special emphasis on the effects of degree zero and one. Journal of Geodesy, 75:283-290

Sjöberg LE (2001b): The effect of downward continuation of gravity anomaly to the sea-level in Stokes' formula. Journal of Geodesy, 74:796-804

Sjöberg LE (2003a): A solution to the downward continuation effect on the geoid determined by Stokes' formula. Journal of Geodesy, 77:94-100

Sjöberg LE (2003b): Improving modified Stokes' formula by GOCE data. Boll Geod Sci Aff 61(3):215-225

Sjöberg LE (2003c): A computational scheme to model geoid by the modified Stokes formula without gravity reductions. Journal of Geodesy, 74:255-268

Sjöberg LE (2003d): A general model of modifying Stokes' formula and its least squares solution. Journal of Geodesy, 77:459-464

Sjöberg LE (2003e): The ellipsoidal corrections to the topographic geoid effects. Journal of Geodesy, 77:804-808

Sjöberg LE (2004): A spherical harmonic representation of the ellipsoidal correction to the modified Stokes formula, Journal of Geodesy, 78(3):1432-1394 
Sjöberg LE (2006): The effects of Stokes' formula for an ellipsoidal layering of the Earth's atmosphere. Journal of Geodesy, 79(12):675-681

Sjöberg LE and Nahavandchi H (2000): The atmospheric geoid effects in Stokes' formula. Geophysical Journal International, 140:95-100

Tscherning, C., Rapp, R., (1974): Closed covariance expressions for gravity anomalies, geoid undulations and deflections of the vertical implied by anomaly degree variance models. Report No. 208, Department of Geodetic Science, Ohio State University, Columbus, $\mathrm{OH}$.

Tsinis D., (2002): Determination of an astrogeodetic geoid model for the Greek region, Postgraduate dissertation, NTUA, School of Rural and Surveying Engineering, Dep. Of Geoinformatics, Athens, Greece

Tziavos I.N. (1984): A study of optimum combination of heterogeneous data for the determination of the geoid: A case study of Greece (PhD Dissertation), Thessaloniki, Greece

Veis G. (1987): The Hellenic Geodetic Reference System. Cadastre and Cartography Agency of Greece, Athens, Greece.

Ågren J (2004): Regional geoid determination methods for the era of satellite gravimetry, Ph.D. Thesis, Royal Institute of Technology, Stockholm, Sweden 


\section{Reports in Geographic Information Technology 2007- 2008}

\section{The TRITA-GIT Series - ISSN 1653-5227}

07-001 Carl Schedlich. Turn at the roundabout: A practical assessment of spatial representations in two different GPS interfaces from a pedestrian's perspective. Bachelor of Science thesis in geoinformatics. Supervisor: Michael Le Duc. January 2007.

07-002 Staffan Bengtsson. Förändringsanalys i ortofoton. Master of Science thesis in geoinformatics. Supervisor: Jonas Nelson and Patric Jansson. TRITA-GIT EX 07-002. March 2007.

07-003 Joseph Addai. Qantification of temporal changes in metal loads - Moss data over 20 years. Master of Science thesis in geoinformatics. Supervisor: Katrin Grunfeld. March 2007.

07-004 Stephen Rosewarne. Deformation study of the Vasa Ship. Bachelor of Science thesis in geodesy No.3097. Suppervisor: Milan Horemuz. March 2007.

07-005 Naeim Dastgir. Processing SAR Data Using Range Doppler and Chirp Scaling Algorithms. Master of Science thesis in geodesy No.3096. Supervisor: Lars Sjöberg. April 2007.

07-006 Torgny Israelsson and Youssef Shoumar. Motion Detection with GPS. Master of Science thesis in geodesy No.3098. Supervisor: Milan Horemuz. April 2007.

07-007 Akjol Djenaliev. Multicriteria decision making and GIS for railroad planning in Kyrgyzstan. Master of Science thesis in geoinformatics. Supervisor: Hans Hauska. May 2007.

07-008 Anna Hammar. Quality comparison of automatic 3D city house modelling methods from laser data. Master of Science thesis in geodesy No.3099. Supervisor: Milan Horemuz. May 2007.

07-009 Md Ubydul Haque. Mapping malaria vector habitats in the dry season in Bangladesh using Spot imagery. Master of Science thesis in geoinformatics. Supervisor: Hans Hauska. May 2007. 
07-010 Jing Jiang. Analysis of the Suitable and Low-Cost Sites for Industrial Land Using Multi Criteria Evaluation: A Case of Panzhihua, China. Master of Science thesis in geoinformatics. Supervisor: Yifang Ban. June 2007.

07-011 Raghavendra Jayamangal. Quantification of coastal erosion along Spey Bay and the Spey River using photogrammetry and LiDAR imagery-derived DTMs. Master of Science thesis in geoinformatics. Supervisor: Yifang Ban and Jim Hansom. June 2007.

07-012 Alicia E. Porcar Lahoz. An analysis of how geographical factors affect real estate prices. Master of Science thesis in geoinformatics. Supervisor: Yifang Ban. October 2007.

07-013 Ebenezer Kwakye Bentum. Detection of land use change in the Accra Metropolitan Area from 1990 to 2000. Master of Science thesis in geoinformatics. Supervisor: Hans Hauska. November 2007.

07-014 Jesper Gradin. Aided inertial navigation field tests using an RLG IMU. Master of Science thesis in geodesy No.3100. Supervisor: Milan Horemuz. December 2007.

08-001 Wan Wen. Road Roughness Detection by analyzing IMU Data. Master of Science thesis in geodesy No.3101. Supervisor: Milan Horemuz. Janaury 2008.

08-002 Ilias Daras. Determination of a gravimetric geoid model of Greece using the method of KTH. Master of Science thesis in geodesy No.3102. Supervisor: Huaan Fan and Kalliopi Papazissi. January 2008. 
TRITA-GIT EX 08-002

ISSN 1653-5227

ISRN KTH/GIT/EX--08/002-SE 